\title{
ADUBAÇÃO NITROGENADA NA CULTURA DO MILHO APLICADA POR UM SISTEMA DE ASPERSÃO EM LINHA
}

\author{
FERNANDO CAMPOS MENDONÇA \\ Engenheiro agrônomo
}

Orientador: Prof. Dr. Tarlei Arriel Botrel

Dissertação apresentada à Escola Superior de Agricultura "Luiz de Queiroz", da Universidade de São Paulo, para obtenção do título de Mestre em Agronomia, Área de Concentração: Irrigação e Drenagem

PIRACICABA

Estado de São Paulo

Agosto - 1994 
Dados Internacionais de Catalogação na Publicação (CIP)

DIVISÃO DE BIBLIOTECA E DOCUMENTAÇÃO - Campus “Luiz de Queiroz"/USP

Mendonça, Fernando Campos

Adubaçāo nitrogenada na cultura do milho aplicada por um sistema

de aspersão em linha / Fernando Campos Mendonça. - - Piracicaba, 1994.

$60 \mathrm{p}$.

Dissertaçāo (mestrado) - - Escola Superior de Agricultura Luiz de Queiroz, 1994.

Bibliografia.

1. Milho - Adubaçāo nitrogenada 2. Fertirrigaçāo 3. Irrigaçāo por aspersāo I. Titulo

CDD $\quad 631.7$

633.18

631.84 


\section{ADUBAÇÃO NITROGENADA NA CULTURA DO MILHO APLICADA POR UM SISTEMA DE ASPERSÃO EM LINHA}

FERNANDO CAMPOS MENDONÇA

Aprovada em: 05/10/1994

Comissão julgadora:

Prof. Dr. Quirino Augusto de Camargo Carmelo

ESALQ/USP

Prof. Dr. Marcus Vinicius Folegatti

ESALQ/USP

Prof. Dr. Tarlei Arriel Botrel

ESALQ/USP

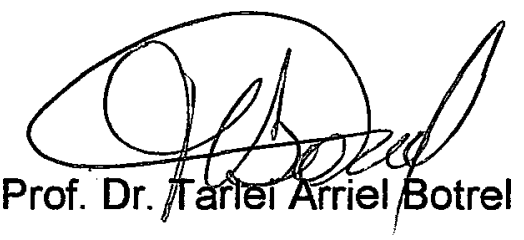

Orientador 
A Janea, minha esposa e companheira em todos os momentos.

A meus pais, Antonio e Antonia, pelos muitos anos de dedicação e luta 


\section{AGRADECIMENTOS}

A Deus, pela vida e por permitir a realização deste trabalho.

À Escola Superior de Agricultura "Luiz de Queiroz", por intermédio do Departamento de Engenharia Rural, pelo curso, apoio e viabilização desta dissertação.

À Coordenadoria de Aperfeiçoamento de Pessoal de Ensino Superior, CAPES, pela contribuição financeira durante a realização do curso.

Ao Professor Dr. Tarlei Arriel Botrel, pela amizade e orientação no decorrer de nossa convivência diária.

Aos colegas Carlos Brancildes Monte Calheiros e Paulo César Silveira Pessoa, pelo auxílio durante o experimento e na preparação da apresentação do trabalho.

Aos funcionários José Figueiredo, Gilmar Grigolon, Hélio de Toledo Gomes e Laudelino Polizel, pela amizade e ajuda sempre valiosas.

Ao Setor de Sementes do Departamento de Agricultura, pela armazenagem e pelo uso do laboratório de sementes para diversas análises.

A todos aqueles que colaboraram direta ou indiretamente na realização deste trabalho. 
SUMÁRIO

Página

LISTA DE FIGURAS vii

LISTA DE TABELAS viii

RESUMO Iix

SUMMARY

1 . INTRODUÇÃO 1

2. REVISÃO DE LITERATURA 3

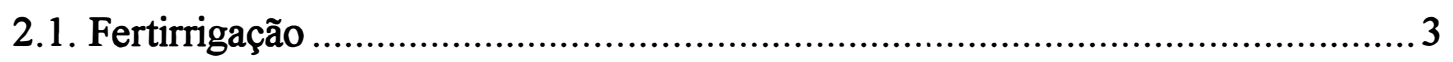

2.1.1. Cuidados com a fertirrigação..................................................... 6

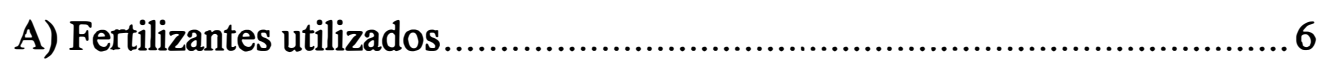

B) Reação dos fertilizantes com a água de irrigação .............................. 7

C) Corrosão: ................................................................................. 7

D) Manejo da fertirrigação: .......................................................... 8

2.1.2. Métodos de introdução de fertilizantes e outros..................................... produtos químicos no sistema de irrigação ..................................... 8

A) Métodos que empregam pressão negativa.................................... 8

B) Métodos que empregam diferença de pressão ................................... 8

C) Métodos que empregam pressão positiva.................................... 9

2.2. Sistema de irrigação por aspersão em linha.............................................. 9

2.3. Cultura do Milho ............................................................................. 13

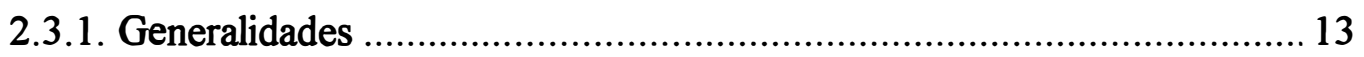

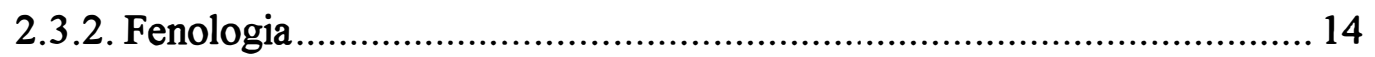

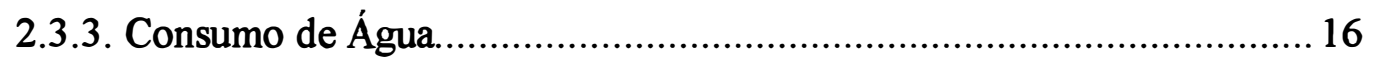

2.3.4. Nutrição Mineral.................................................................... 17 
2.4. Delineamento e Análise Estatística

3. MATERIAL E MÉTODOS 23

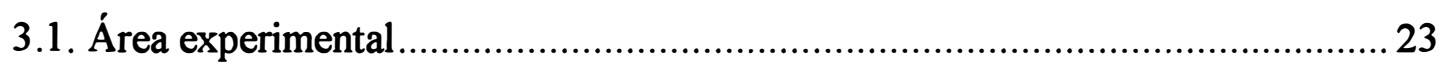

3.2. Caracterização do solo e controle da irrigação ................................................ 23

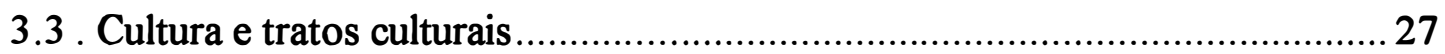

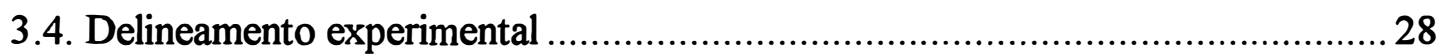

3.5. Equipamento de irrigação e aplicação do fertilizante ......................................29

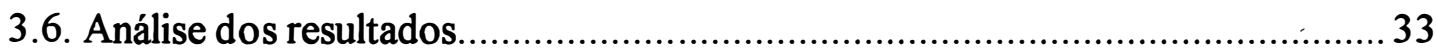

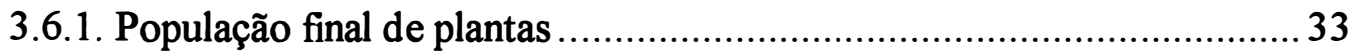

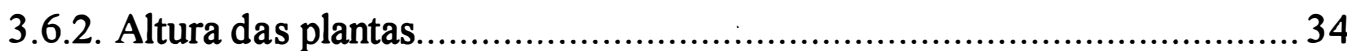

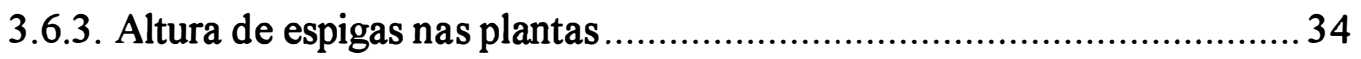

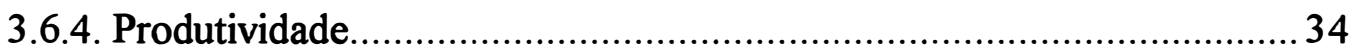

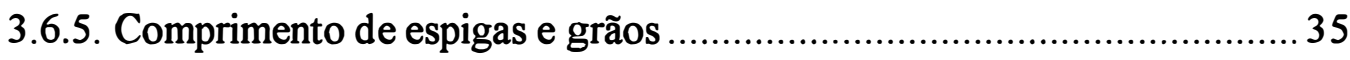

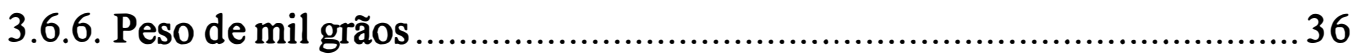

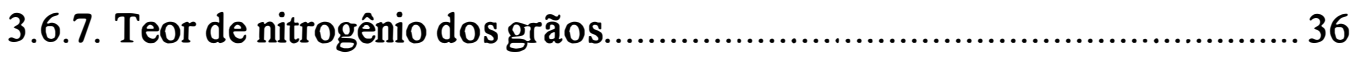

3.6.8. Função de produção para o fator dose de nitrogênio ............................... 37

4. RESULTADOS E DISCUSSÃO 39

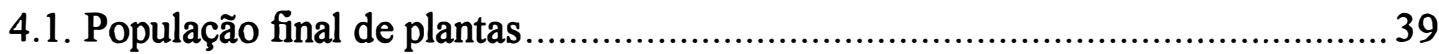

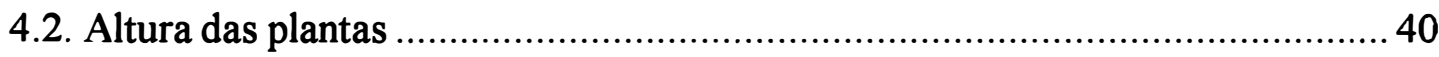

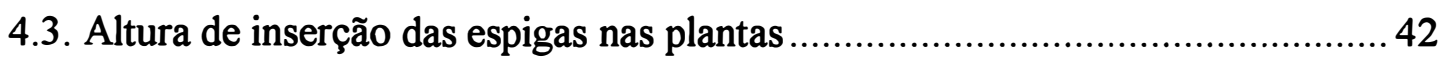

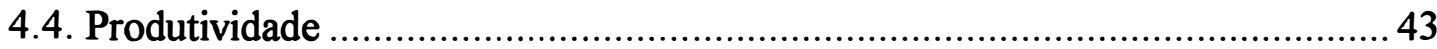

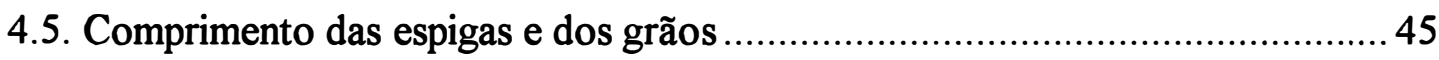

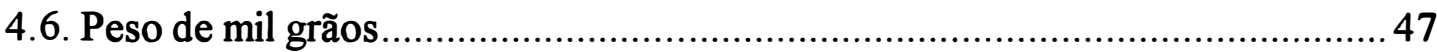

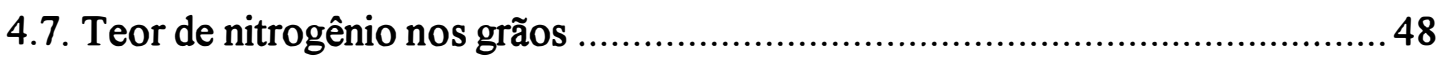

4.8. Função de produção para o fator doses de nitrogênio .........................................49

5. CONCLUSÕES

6. REFERÊNCIAS BIBLIOGRÁFICAS 


\section{LISTA DE FIGURAS}

Página

Figura 1 - Área experimental e equipamento de irrigação ......................................... 28

Figura 2 - Parcela experimental e área útil da parcela .......................................... 29

Figura 3 - Perfil de distribuição de água e fertilizante ............................................ 30

Figura 4 - Tanque de aplicação de fertilizantes................................................ 30

Figura 5 - Distribuição de coletores na área experimental....................................... 33

Figura 6 - Evolução da altura de plantas ao longo do ciclo..................................... 41

Figura 7 - Produtividade da cultura do milho em função ............................................

da dose de nitrogênio ................................................................. 45 
LISTA DE TABELAS

\section{Página}

TABELA 1 - Solubilidade e composição de fertilizantes ............................................... 4

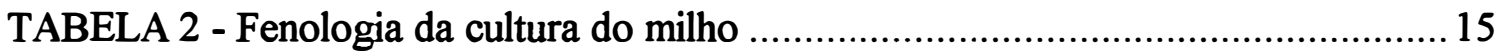

TABELA 3 - Extração de nutrientes $(\mathrm{Kg} / \mathrm{ha})$ pelo milho em diferentes

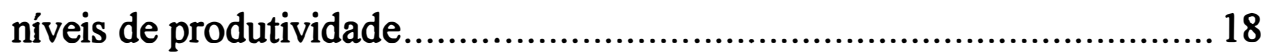

TABELA 4 - Parâmetros de ajuste da curva de retenção de água no solo à equação de Van Genuchten ............................................................... 24

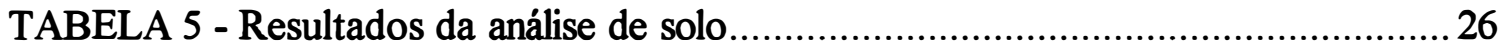

TABELA 6 - Recomendações técnicas para adubação de plantio ................................... 26

TABELA 7 - População final do experimento (pl./ha).................................................39

TABELA 8 - Evolução da média da altura das plantas (m) nos tratamentos, ao longo.. 40

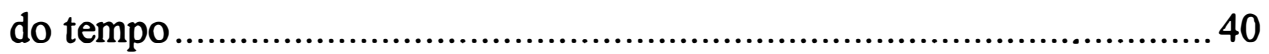

TABELA 9 - Altura de inserção das espigas nas plantas (m) .................................... 43

TABELA 10 - Produtividade da cultura do milho no experimento ( $\mathrm{Kg} / \mathrm{ha})$...................4 44

TABELA 11 - Comprimento de espigas dos tratamentos $(\mathrm{mm})$....................................46

TABELA 12 - Comprimento de grãos em cada tratamento (mm) ................................ 46

TABELA 13 - Peso de mil grãos em cada tratamento (g)............................................. 47

TABELA 14 - Teor de nitrogênio (\%) nos grãos de cada tratamento ............................ 48

TABELA 15 - Dose média de nitrogênio aplicada em cada tratamento .........................50

TABELA 16 - Dados observados e estimados de produção em função da dose de nitrogênio 


\title{
ADUBAÇÃO NITROGENADA NA CULTURA DO MILHO APLICADA POR UM SISTEMA DE ASPERSÃO EM LINHA
}

\author{
Autor: FERNANDO CAMPOS MENDONÇA \\ Orientador: PROF. DR. TARLEI ARRIEL BOTREL
}

\section{RESUMO}

O presente estudo teve por objetivo o estudo do efeito do nitrogênio na cultura do milho, quando aplicado através da água de irrigação, na adubação de cobertura. O trabalho foi realizado em área do Departamento de Engenharia Rural da Escola Superior de Agricultura "Luiz de Queiroz", da Universidade de São Paulo, campus de Piracicaba.

Foi utilizado o milho híbrido duplo precoce AG-303, com uma adubação de plantio de $23 \mathrm{Kg} \mathrm{N} / \mathrm{ha}, 80 \mathrm{Kg}_{2} \mathrm{O}_{5} / \mathrm{ha}$ e $46 \mathrm{Kg} \mathrm{K}_{2} \mathrm{O} / \mathrm{ha}$. O plantio foi feito no dia 25/10/1993. O fertilizante utilizado na adubação de cobertura foi a uréia, aplicada através de um sistema de irrigação por aspersão em linha ("line source sprinkler system"). Foi usado um tanque de derivação para introduzir o fertilizante na tubulação dos sistema de irrigação. O sistema de irrigação constituiu-se de 3 linhas com 4 aspersores cada uma, espaçados de 6 metros entre si e 12 entre linhas. Este sistema teve características de aspersão em linha apenas para a aplicação do fertilizante. As linhas externas aplicaram água e fertilizante, enquanto a linha central aplicou apenas água. 
Conseguiu-se, assim, doses decrescentes de nitrogênio na direção perpendicular às linhas externas de aspersores, no sentido de afastamento dessas linhas. A lâmina de água foi uniforme para toda a área. A área experimental foi dividida em quatro blocos de oito tratamentos, no sentido da maior declividade. Os tratamentos foram as doses totais de nitrogênio aplicadas em cobertura.

Os parâmetros medidos para análise de resultados foram: altura de plantas, altura de inserção das espigas nas plantas, produtividade, comprimento de espigas e de grãos, peso de mil grãos e teor de nitrogênio nos grãos. Os resultados obtidos mostraram que apenas o comprimento de grãos não foi afetado pela dose de nitrogênio. $O$ nitrogênio afetou tanto os aspectos quantitativos quanto os qualitativos dos grãos. $\mathrm{O}$ aumento da dose de nitrogênio aumentou a produtividade até um certo limite, a partir do qual houve decréscimo na produção. Estimou-se uma função de produção da cultura do milho para o fator dose de nitrogênio. Para as condições do experimento, a função de produção estimada foi do tipo exponencial quadrática, através da qual foi obtido o ponto de máxima produtividade $(7.663,65 \mathrm{Kg}$ grãos/ha), que foi obtido com uma dose de $242,6 \mathrm{Kg}$ N/ha.

O sistema de aspersão em linha mostrou-se apropriado para a condução de experimentos de fertirrigação, desde que se evite o excesso de vento e que o equipamento seja montado paralelamente à direção predominante do vento. 


\title{
NITROGEN FERTILIZATION EFFECT ON CORN CROP, APPLIED BY A LINE-SOURCE SPRINKLER SYSTEM
}

\author{
Author: FERNANDO CAMPOS MENDONÇA
}

Adviser: PROF. DR. TARLEI ARRIEL BOTREL

\section{SUMMARY}

The present study aimed the study of nitrogen effects on corn crop, when the fertilizer is applied within the water, by fertigation. The work was accomplished in an area of the Rural Engineering Department of the 'Escola Superior de Agricultura Luiz de Queiroz" , “Universidade de São Paulo”, campus Piracicaba, São Paulo.

The corn cultivar used was the hybrid AG-303. A planting fertilization was made using $23 \mathrm{Kg} \mathrm{N} / \mathrm{ha}, 80 \mathrm{Kg} \mathrm{P}_{2} \mathrm{O}_{5} / \mathrm{ha}$, and $46 \mathrm{Kg} \mathrm{K}_{2} \mathrm{O} / \mathrm{ha}$. The planting was made at October, 25th, 1993. The fertilizer used on the recovering fertilization was urea, applied through a line-source sprinkler system. A pressurized derivation tank was used on the fertilizer introductionin the irrigation tubes. The irrigation system (conventional sprinkler system) had three laterals with four sprinklers spaced by six meters, and the laterals spaced by twelve meters. This system was operated as a line-source only for the fertilizer application (fertigation). The external laterals applied water and fertilizer, 
whereas the lateral line in the center of the area applied only water. This provided decreasing levels of nitrogen with the increase of distance at the perpendicular direction of the laterals. The water depth was uniform at all the experiment area, which was dividedin four blocks, with eight treatments each of them. The treatments were the total recovering nitrogen fertilizer applied $(\mathrm{Kg} / \mathrm{ha})$.

The measured parameters for the result analysis were: plant height, corncob inserction height, productivity, the corn-cob length, and grain length. The results showed that only the grain length wasn't affected by the nitrogen level. Nitrogen affected both, quantity and quality aspects of the corn grains. Increasing nitrogen levels increased the productivity, till a certain limit, beyon from which the incresing of nitrogen decreased the grain yeld. It was estimated a crop production function for the nitrogen level factor. On the experimental conditions, the crop production function that gave better results was an exponential quadratic model, through that it was obtained the nitrogen level for the biggest produtivity ( $242.6 \mathrm{Kg} \mathrm{N} / \mathrm{ha}$ and $7,663.65 \mathrm{Kg} / \mathrm{ha}$ ).

Line-source sprinkler system proved to be an appropriate method for fertigation studies, since that be avoided the excessive wind velocity, and the equipment be mounted on the paralel predominant wind direction. 


\section{1 . INTRODUÇÃO}

A irrigação é uma técnica que pode contribuir para o aumento da produtividade de diversas culturas, modificando o sistema de produção agrícola.

Dentre as modificações possiveis na estrutura de produção pode-se incluir a forma de aplicação de diversos produtos químicos às culturas, como inseticidas, herbicidas, fungicidas e fertilizantes.

É possível aplicar esses produtos através de sistemas de irrigação, diminuindo o trânsito de máquinas nos campos de produção, parcelando melhor a aplicação e permitindo a economia de combustiveis usados na execução das aplicações. Esta técnica é chamada de quimigação.

Das modalidades da quimigação, a mais utilizada é a fertirrigação, ou seja, a aplicação de fertilizantes via água de irrigação. Esta técnica vem sendo bastante divulgada, tendo em vista a sua utilidade. A obtenção de resultados de pesquisa a respeito desta técnica é importante para que ela possa ser melhor aproveitada.

No caso de nutrientes muito móveis, como o nitrogênio, a fertirrigação possibilita uma 
A qualidade da fertirrigação está ligada às características do sistema de irrigação utilizado. A distribuição adequada desses produtos depende da eficiência de distribuição do sistema de irrigação utilizado.

No caso dos sistemas de irrigação por aspersão convencional, a eficiência de distribuição de água e de fertilizantes é determinada pelo perfil de distribuição de água do emissor utilizado e pela disposição do equipamento no campo.

Uma técnica que permite boa visualização dos resultados da aplicação de diversas lâminas de água às culturas é a utilização do sistema de aspersão em linha ("line source sprinkler system"). Esse sistema permite a aplicação de lâminas decrescentes de água em direção perpendicular à da linha de aspersores, possibilitando o estudo dos resultados dessa aplicação em uma área relativamente pequena.

Estando o fertilizante dissolvido na água de irrigação, a distribuição dos nutrientes contidos nele acompanhará o perfil de distribuição de água do emissor utilizado, desde que o escoamento seja turbulento. Assim, o sistema de aspersão em linha também pode ser usado para estudos de diferentes níveis de adubação via água de irrigação.

O objetivo deste trabalho foi o estudo do efeito de doses decrescentes de nitrogênio na cultura do milho, utilizando um sistema de irrigação por aspersão em linha ("line source sprinkler system") para aplicação do fertilizante. 


\section{2 . REVISÃO DE LITERATURA}

\subsection{Fertirrigação}

MAIA et al(1990) definiram a quimigação como sendo a aplicação de fertilizantes, inseticidas, fungicidas e herbicidas às plantas via água de irrigação. Os autores assumiram como regra geral que todos os sistemas de irrigação podem ser utilizados para a aplicação desses produtos químicos. Os métodos que apresentam maior facilidade de manejo e maior uniformidade de distribuição de água são os mais adequados à utilização da fertirrigação. Costuma-se usar principalmente os sistemas de irrigação localizada, o pivô central e a aspersão convencional.

A fertirrigação é uma das modalidades da quimigação. $\mathrm{O}$ termo define a aplicação de fertilizantes através da água de irrigação. DOURADO NETO et al.(1991) relataram que o início da fertirrigação se deu na década de 30 , com irrigação por aspersão, na Califórnia (EUA). VIETS JR. et al(1967) relataram um grande avanço da fertirrigação a partir do desenvolvimento dos equipamentos de irrigação (pivô central e rrigação localizada) e com o advento dos adubos líquidos, principalmente o fertilizante amoniacal (amônia anidra). 
DOURADO NETO et al.(1991) citaram algumas características desejáveis dos fertilizantes para uso em fertirrigação: solubilidade rápida e completa, baixa capacidade corrosiva, baixa volatilidade e toxicidade, alta concentração, disponibilidade de informações de pesquisa, disponibilidade no mercado, fácil manipulação, boa compatibilidade em misturas de adubos e baixo custo.

A solubilidade é um fator importante na escolha dos fertilizantes. A Tabela 1 apresenta a solubilidade e a composição média de diversos fertilizantes. $\mathrm{Na}$ aplicação conjunta de vários fertilizantes deve-se observar a sua compatibilidade, para evitar problemas de precipitação de produtos nas tubulações e emissores.

TABELA 1 - Solubilidade e composição de fertilizantes

\begin{tabular}{|c|c|c|c|c|c|}
\hline \multirow{2}{*}{$\begin{array}{c}\text { MACRONUTRIENTES } \\
\text { (FERTILIZANTES) }\end{array}$} & \multirow[t]{2}{*}{ P.S. ${ }^{*}$} & \multicolumn{4}{|c|}{ COMPOSIÇÃO MÉDIA (\%) } \\
\hline & & $\mathrm{N}$ & $\mathbf{P}$ & $\mathrm{K}$ & \\
\hline $\mathrm{NH}_{4} \mathrm{NO}_{3}$ & 128 & 32,0 & --- & ---- & \\
\hline$\left(\mathrm{NH}_{4}\right)_{2} \mathrm{SO}_{4}$ & 71 & 20,0 & $\cdots$ & $-\cdots$ & \\
\hline $\mathrm{Ca}\left(\mathrm{NO}_{3}\right)_{2}$ & 102 & 15,5 & --- & --- & $(21 \% \mathrm{Ca})$ \\
\hline DAP & 43 & 16,0 & 45,0 & --.- & \\
\hline MAP & 23 & 9,0 & 48,0 & & \\
\hline $\mathrm{KCl}$ & 34 & ---- & ---- & 58,0 & \\
\hline $\mathrm{KNO}_{3}$ & 32 & 13,0 & ---- & 13,5 & \\
\hline $\mathrm{K}_{2} \mathrm{SO}_{4}$ & 11 & ---- & ---- & 48,0 & $(18 \% S)$ \\
\hline URÉIA & 78 & $45-46$ & --- & ---- & \\
\hline MICRONUTRIENTES & P.S. ${ }^{*}$ & \multicolumn{4}{|c|}{ COMPOSIÇÃO MÉDIA (\%) } \\
\hline $\mathrm{CuSO}_{4}$ & 22 & \multicolumn{4}{|c|}{$25 \% \mathrm{Cu}$} \\
\hline Borato de Sódio & 5 & \multicolumn{4}{|c|}{$11 \% \mathrm{~B}$} \\
\hline Molibdato Sódio & 56 & \multicolumn{4}{|c|}{$30 \%$ Mo } \\
\hline $\mathrm{ZnSO}_{4}$ & 75 & \multicolumn{4}{|c|}{$22 \% \mathrm{Zn}$} \\
\hline
\end{tabular}

* P.S.: partes solubilizadas em 100 partes de água a $20^{\circ} \mathrm{C}$

FONTE : SHAW (1961) 
MAIA et al(1990), SEGARS(1982), PAIR et al(1969), VIETS et al(1967) e COSTA et al(1986) citaram como vantagens da fertirrigação: economia de mão-de-obra e maquinaria, melhor uso dos equipamentos de irrigação, maior controle e eficiência dos equipamentos de aplicação de fertilizantes, maior parcelamento na aplicação dos fertilizantes, menor dano físico ao solo e à cultura, maior uniformidade de distribuição do fertilizante aplicado, maior flexibilidade das operações, simplificação das práticas culturais e maior eficiência de utilização dos nutrientes.

FREY(1981) afirmou que com a fertirrigação os gastos com fertilizantes podem ser reduzidos à metade ou à terça parte da quantidade usada em outros métodos. BARROS et al(1977) encontraram uma redução dos custos de aplicação de fertilizantes usando a fertirrigação. BAR-YOSEF(1977) afirmou que com a fertirrigação pode-se fazer uma adubação eficiente em solos arenosos,o que nem sempre é possível devido à baixa capacidade de troca de cátions (CTC) e à alta permeabilidade desses solos, causando grandes perdas por lixiviação.

FRIZZONE(1984) afirmou que a aplicação convencional de fertilizantes é relativamente demorada,podendo causar a compactação do solo, e que a fertirrigação é bastante cômoda e rápida. A solução de fertilizante dilui-se de forma homogênea na água de irrigação, distribuindo-se com ela pelo campo. Observou que o fracionamento da aplicação de fertilizantes tem influência decisiva no rendimento das culturas, aumentando a sua assimilação relativa pelas plantas e reduzindo as perdas por lixiviação.

HAGIN \& TUCKER(1982) afirmaram que a fertirrigação tem mais 
vantagens em solos de textura grosseira do que nos de textura fina, principalmente para fertilizantes nitrogenados.

\subsubsection{Cuidados com a fertirrigação}

MAIA et al(1990) afirmaram que alguns cuidados devem ser tomados com relação à fertirrigação, sendo eles apresentados nos itens a seguir.

\section{A) Fertilizantes utilizados}

A fertirrigação é apropriada para o uso de produtos em solução ou de alta solubilidade. Há vantagens para os nutrientes que se movem com a água do solo (fluxo de massa), tais como o nitrogênio, o enxofre e alguns micronutrientes.

MAIA et al(1990) citaram os principais fertilizantes utilizados na fertirrigação:

\section{nitrogenados:}

sulfato de amônio - $\left(\mathrm{NH}_{4}\right)_{2} \mathrm{SO}_{4}-20,5 \% \mathrm{~N} ; 20,4 \% \mathrm{~S}$;

nitrato de amônio - $\mathrm{NH}_{4} \mathrm{NO}_{3}-34 \% \mathrm{~N}$;

solução nitrogenada - URAN $\left(\mathrm{NH}_{4} \mathrm{NO}_{3}+\right.$ Uréia $)-32 \% \mathrm{~N}$; uréia $-45 \% \mathrm{~N}$;

potássicos:

nitrato de potássio $\left(\mathrm{KNO}_{3}-46 \% \mathrm{~K}_{2} \mathrm{O} ; 13 \% \mathrm{~N}\right)$

cloreto de potássio $\left(\mathrm{KCl}-60 \% \mathrm{~K}_{2} \mathrm{O}\right)$

sulfato de potássio $\left(\mathrm{K}_{2} \mathrm{SO}_{4}-52 \% \mathrm{~K}_{2} \mathrm{O}\right)$

\section{fosforados:}

fosfato de amônio ( $\left(\mathrm{NH}_{4}\right)_{3} \mathrm{PO}_{4}-10 \% \mathrm{~N} ; 30 \% \mathrm{P}_{2} \mathrm{O}_{5}$ )

fosfato monoamônio - MAP ( $\left.11 \% \mathrm{~N} ; 49 \% \mathrm{P}_{2} \mathrm{O}_{5}\right)$

fosfato diamônio - DAP ( $\left.19 \% \mathrm{~N} ; 45 \% \mathrm{P}_{2} \mathrm{O}_{5}\right)$ 


\section{misturas:}

$$
\begin{aligned}
& 9 \% \mathrm{~N}+48 \% \mathrm{P}_{2} \mathrm{O}_{5} \\
& 16 \% \mathrm{~N}+45 \% \mathrm{P}_{2} \mathrm{O}_{5} \\
& 8 \% \mathrm{~N}+24 \% \mathrm{P}_{2} \mathrm{O}_{5} \\
& \mathrm{MAP}+\mathrm{KNO}_{3}+\mathrm{KCl}\left(10 \% \mathrm{~N}+10 \% \mathrm{P}_{2} \mathrm{O}_{5}+10 \% \mathrm{~K}_{2} \mathrm{O}\right)
\end{aligned}
$$

Dentre os fertilizantes nitrogenados, a uréia tem sido bastante utilizada na fertirrigação. Apresenta pH 7,6 quando em solução, baixa corrosividade em diversos materiais (ferro galvanizado, alumínio, aço inox, bronze, latão e outros) e possibilidade de mistura com diversos fertilizantes.

\section{B) Reação dos fertilizantes com a água de irrigação}

A qualidade da água e os produtos a serem aplicados devem ser estudados antecipadamente, visando evitar a formação de precipitados, principalmente em irrigação localizada. Pode haver problemas de entupimento na tubulação, afetando a distribuição adequada de água.

\section{C) Corrosão:}

Para diminuir os efeitos da corrosão por fertilizantes no sistema de irrigação, duas medidas são muito importantes. A primeira é usar soluções de baixas concentrações, o que é perfeitamente possível devido ao grande volume de água utilizado. A segunda é realizar a irrigação normal após a fertirrigação, para retirar os resíduos químicos do sistema de irrigação. 


\section{D) Manejo da fertirrigação:}

MAIA et al(1990) afirmaram que o manejo da fertirrigação deve ser feito de forma a evitar a lixiviação de nutrientes abaixo da zona radicular. A fertirrigação possibilita a aplicação parcelada de fertilizantes e a redução da lixiviação de nutrientes móveis no perfil do solo. Os autores recomendaram uma lavagem do sistema de irrigação e a remoção dos resíduos de fertilizantes das folhas das plantas após a fertirrigação.

\subsubsection{Métodos de introdução de fertilizantes e outros produtos químicos no sistema de irrigação}

MAIA et al (1990) afirmaram que há vários métodos de introdução de produtos químicos nos sistemas de irrigação, os quais estão agrupados em três tipos: métodos que empregam pressão negativa, métodos que empregam diferença de pressão e métodos que empregam pressão positiva.

\section{A) Métodos que empregam pressão negativa}

A entrada dos produtos químicos no sistema de irrigação se dá pela tubulação de sucção, com controle do fluxo através de registro. Apresenta o inconveniente de promover um contato direto da solução com as partes internas da bomba, podendo causar corrosão de suas peças e/ou contaminação da fonte de água. Por outro lado, são sistemas de baixo custo de instalação.

\section{B) Métodos que empregam diferença de pressão}

Há dois equipamentos que utilizam a diferença de pressão e são 
comumente utilizados: o tanque de derivação e o aplicador tipo Venturi. O princípio de funcionamento do primeiro baseia-se na derivação de parte do fluxo para passar por um tanque pressurizado contendo fertilizante. No caso do aplicador tipo Venturi, o princípio de funcionamento é a transformação de energia piezométrica (pressão) em energia de velocidade.

\section{C) Métodos que empregam pressão positiva}

Sua pressão é superior à do sistema de irrigação. Promove-se, assim, a entrada do fertilizante na rede, chegando às plantas. São os métodos mais precisos, permitindo um melhor controle do ritmo de injeção e eliminação de perdas de pressão na rede de irrigação. A solução é armazenada em tanque aberto, de onde é succionada posteriormente para injeção. A bomba injetora usa pressão da própria rede de irrigação, motor elétrico ou de combustão interna para seu acionamento.

\subsection{Sistema de irrigação por aspersão em linha}

O sistema de aspersão em linha ("line source sprinkler system") tem sido utilizado em diversos estudos sobre lâmina de irrigação e produtividade, contribuindo grandemente para a determinação de funções de produção das culturas. Constitui-se de uma linha lateral instalada no centro da área, com aspersores estreitamente espaçados entre si. Há uma sobreposição dos jatos de água, gerando maior precipitação junto à linha de aspersores e gradiente decrescente ao longo da direção perpendicular à tubulação. 
HANKS et al(1980) afirmaram que o objetivo do uso do sistema de aspersão em linha é viabilizar a obtenção de resultados quantitativos para determinar funções de produção de água, aliada ou não a outros fatores (fertilizantes e/ou variedades, principalmente). Os autores também afirmaram que os outros fatores podem ser estudados pela distribuição aleatória de tratamentos em faixas perpendiculares aos tratamentos de irrigação.

FRIZZONE(1986) afirmou que o sistema de aspersão em linha tem apresentado uma boa performance na geração de diversas lâminas de água, em áreas menores que outros sistemas de irrigação. $\mathrm{O}$ autor também afirmou que há uma melhor visualização do efeito dos tratamentos no campo de pesquisa. FRIZZONE(1986) e FARIA(1981) citaram as seguintes vantagens da utilização do sistema de aspersão em linha: economia de área, equipamento e mão-de-obra, facilidade de instalação e operação, e maior número de tratamentos em área menor do que no sistema de aspersão convencional.

O tipo de aspersor utilizado determina o perfil de distribuição de água na área experimental. É desejável que esse perfil tenha forma triangular, para facilitar a determinação da lâmina média em cada faixa perpendicular à linha de aspersores. Para o bom andamento das pesquisas, são necessários testes prévios com os aspersores para determinação de suas características de distribuição de água (diâmetro molhado, perfil de distribuição de água e características de vazão e pressão). As parcelas experimentais devem estar dispostas perpendicularmente em relação à linha de irrigação, para que 
recebam diferentes lâminas de água.

Estudos feitos com o sistema de aspersão em linha indicaram que seu uso pode estender-se ao estudo de diferentes doses de produtos químicos aplicadas através da água de irrigação (quimigação). Os produtos aplicados por quimigação devem ser solúveis em água e, portanto, acompanhar a distribuição de água do sistema de irrigação utilizado.

LAUER (1983) utilizou um sistema denominado "triple line source" no estudo da distribuição de fertilizantes nitrogenados, injetando o fertilizante apenas na linha central do sistema. As outras duas linhas proporcionaram homogeneidade da lâmina de água na área experimental, enquanto a dose de fertilizante nitrogenado variou perpendicularmente com a distância da linha central de aspersores.

MORKOC et al(1985) fizeram uma análise matemática da produção de sorgo (Sorghum bicolor [L.] Moench) irrigado por um sistema de aspersão em linha, denominado "double line source", com duas doses de salinidade da água de irrigação. Uma linha de aspersores aplicou água pura, e a outra, água salinizada, homogeneizando a distribuição de água na área experimental, enquanto o teor de salinidade variou perpendicularmente com a distância da linha de aspersores que aplicou água salina. As respostas produtivas da cultura no experimento foram explicadas por uma função de produção de segundo grau (resposta quadrática).

BROADBENT et al(1988) utilizaram um procedimento semelhante para avaliar a influência de gradientes de salinidade e umidade na utilização do solo e do 
fertilizante nitrogenado pelas culturas do sorgo e do trigo. Os autores concluíram que o estresse hídrico teve maior influência na produção do que o estresse por salinidade, apesar de a camada de solo utilizada para medir os teores de água e salinidade não ser representativa de toda a zona radicular.

MAGNUSSON et al(1988) utilizaram dois sistemas "triple line source" no estudo dos efeitos interativos de águas de irrigação com diferentes graus de salinidade e concentrações de nitrato de amônio na produção da cultura do milho. MAGNUSSON \& ASHER (1990) conceberam um modelo computacional para auxiliar a avaliação dos níveis multivariáveis em contínua mudança produzidos pelo sistema de aspersão em linha.

FRENKEL et al(1990) utilizaram um conjunto de bocais de diferentes tamanhos e águas classificadas em diversos níveis de qualidade em um sistema "double line source" para determinar os efeitos individuais e interativos da água e salinidade em milho forrageiro.

ARAGÜÉS et al(1992) afirmaram que os sistemas denominados "double" ou "triple line source" podem ser um método prático de criação e manutenção de gradientes de salinidade para estudo de seus efeitos nas culturas, desde que sejam respeitadas algumas premissas: a) o sistema de irrigação deve ser instalado paralelamente à direção do vento predominante, e sua operação deve ser feita sob condições de baixa velocidade do mesmo (menor ou igual a $2 \mathrm{~m} / \mathrm{s}$ ); b) altas frações de lixiviação são necessárias ao estabelecimento mais rápido de gradientes de salinidade, bem como para a 
obtenção de perfis uniformes de salinidade do solo; e c) a absorção foliar de sais pelas plantas deve estar abaixo dos níveis tóxicos, o que pode ser minimizado pela aplicação de água pura por um período curto, feita logo após cada ciclo de aplicação de água salina, promovendo a lavagem das folhas das plantas.

\subsection{Cultura do Milho}

\subsubsection{Generalidades}

Segundo CAMARGO(1966), o milho é cultivado desde a latitude $58^{\circ} \mathrm{N}$ (Canadá e Rússia) até $40^{\circ} \mathrm{S}$ (Argentina), devido ao grande número de variedades e híbridos existentes. KRUG(1966) observa que o milho já existia há pelo menos cinco mil anos, no México e no Estado do Novo México (EUA). Constitui alimento básico para grande parte da população mundial, sendo uma espécie que apresenta grande heterogeneidade genética. Sua produtividade tem crescido bastante devido ao intenso trabalho de melhoramento e adaptação genéticos que vem sofrendo.

SILVA et al(1987) afirmaram que o milho é a cultura mais largamente plantada no Brasil, com cerca de doze milhões de hectares cultivados, embora seu rendimento médio no país seja ainda bastante baixo.

A cultura do milho tem sido muito estudada, visando a determinação dos diversos fatores que influenciam sua produção, tais como exigências nutricionais e hídricas, fenologia, área foliar, pragas, doenças e outros.

Devido à sua grande importância como alimento humano ou animal, é 
necessário um constante aprimoramento das técnicas de produção, visando atender às necessidades de consumo.

KRUG(1966) acentuou a necessidade de pesquisas com esse vegetal nos trópicos, principalmente no sentido de aumentar sua produtividade, o que tem sido feito com êxito. É importante lembrar que não apenas a produtividade, mas também a qualidade do produto obtido está sendo estudada.

\subsubsection{Fenologia}

FANCELLI(1986) descreveu o ciclo da cultura do milho, dividindo-o em fases do desenvolvimento das plantas, conforme mostra a Tabela 2, cujo objetivo é possibilitar o estabelecimento de correlações entre elementos que influenciam a produção (fisiologia, clima, genética, entomologia, fitopatologia, técnicas de cultivo e outros).

VIÉGAS(1966) afirmou que o milho apresenta uma fase crítica de desenvolvimento logo após a germinação, durante a qual não deve sofrer concorrência de ervas daninhas pela absorção de fertilizantes e água. Essa fase vai da germinação até a planta atingir aproximadamente $40 \mathrm{a} 50 \mathrm{~cm}$ de altura.

Segundo FANCELLI(1991), o milho apresenta algumas fases críticar que podem comprometer o resultado final do seu cultivo. Um estresse hídrico próximo a estádio 2 (plantas com 8 folhas) pode afetar o comprimento e diâmetro dos internódios, pela inibição da elongação das células em desenvolvimento, concorrendo para a diminuição da capacidade de fotoassimilados no colmo. 
TABELA 2 - Fenologia da cultura do milho

\begin{tabular}{|c|c|c|}
\hline FASE & ESTÁDIO & CARACTERIZAÇÃO DO ESTÁDIO \\
\hline \multirow{5}{*}{ VEGETATIVA } & $0(1 \mathrm{~s})$ & Emergência e aparecimento do coleóptilo \\
\hline & $1(2 s)$ & 4 folhas totalmente desdobradas \\
\hline & $2(4 s)$ & $7-8$ folhas totalmente desdobradas \\
\hline & $3(6 s)$ & 12 folhas totalmente desdobradas \\
\hline & $4(8 \mathrm{~s})$ & Emissão do pendão floral (panícula) \\
\hline \multirow{6}{*}{ REPRODUTIVA } & $5(9-10 s)$ & Abertura das flores e início da polinização \\
\hline & $6(12 d)$ & Grãos leitosos \\
\hline & $7(24 d)$ & Grãos pastosos \\
\hline & $8(36 d)$ & Grãos pastosos-farináceos \\
\hline & $9(48 d)$ & $\begin{array}{l}\text { Grãos farináceos (duros) e morfologicamente } \\
\text { maduros }\end{array}$ \\
\hline & $10(55 \mathrm{~d})$ & $\begin{array}{l}\text { Grãos farináceos (duros) e fisiologicamente } \\
\text { maduros }\end{array}$ \\
\hline
\end{tabular}

Fonte : FANCELLI(1986)

Entre a nona e a décima semana inicia-se, normalmente, o florescimento, com acentuada dependência das condições climáticas favoráveis. HENCKEL(1964) afirmou que se houver deficiência hídrica uma semana após a emissão das anteras, pode ocorrer uma queda de 50\% na produção. Deficiências hídricas posteriores ao início da polinização resultarão em danos da ordem de 25 a $30 \%$.

O estádio 6 (grãos leitosos) marca o início do processo de acúmulo de substâncias de reserva no endosperma. A baixa disponibilidade de água pode afetar muito a definição do peso do grão e a formação do embrião.

Uma deficiência hídrica no estádio 7 (grãos pastosos) pode causar uma maior quantidade de grãos leves e de menor tamanho. Outros fatores decisivos no 
resultado final são a distribuição de chuvas, a disponibilidade de nutrientes e a duração do período compreendido entre os estádios 3 e 5 (12 folhas até início da polinização).

\subsubsection{Consumo de Água}

Segundo KEEPER(1966), as melhores colheitas de milho se dão quando este é plantado em solos com estrutura granular bem desenvolvida, soltos ou friáveis e com boa permeabilidade à água e ao ar. $\mathrm{O}$ autor também afirma que o milho suporta mal a seca, apesar da necessidade relativamente pequena de água por unidade de matéria seca produzida. A planta também apresenta tolerância a solos moderadamente drenados, mas em geral não suporta encharcamento. VASCONCELLOS et al(1987) confirmam estas afirmações, observando que apesar de se poder cultivar o milho em diferentes tipos de solo, os rendimentos serão mais elevados nos solos mais profundos, férteis, com boa drenagem e aeração.

DOOREMBOS \& KASSAN(1979) afirmam que um cultivar de milho de ciclo médio requer de 500 a 800 milímetros de água para uma boa produção. SHAW(1977) estudou os resultados obtidos por diferentes autores e afirmou que o consumo de água pelo milho varia de 410 a 640 milímetros. DOWNEY(1971), estudando a evapotranspiração na cultura do milho, encontrou um total de 560 milímetros, valor este que não foi afetado significativamente pela densidade de plantio. FANCELLI(1991) afirma que há uma exigência mínima de 300 a 350 milímetros de água para uma produção satisfatória sem uso de irrigação. $O$ autor lembra também que as 
limitações hídricas acham-se mais condicionadas à distribuição de precipitação. Estresses hídricos podem ocasionar redução no vigor vegetativo e na altura da planta, bem como na produção e fertilidade do pólen, além de alterar sobremaneira o sincronismo de aparecimento das inflorescências masculina e feminina.

FRATTINI(1975) definiu os períodos de maior exigência hídrica do milho. São eles: emergência, florescimento e formação dos grãos. Dentre estes, o autor definiu como crítico o período que vai de quinze dias antes a quinze dias após o aparecimento da inflorescência masculina. Nesse período é desejável que haja temperaturas favoráveis, entre 25 a $30^{\circ} \mathrm{C}$, além de não haver falta de água. DAKER(1970) afirma que o consumo de água na cultura do milho em clima quente e seco raramente ultrapassa $2,5 \mathrm{~mm} /$ dia em plantas com altura inferior a 30 centímetros. No período que vai do espigamento à maturação, entretanto, esse consumo pode ser de 5 a $7,5 \mathrm{~mm} /$ dia. $\mathrm{O}$ autor afirma que algumas pesquisas mostram índices diários de 10 milimetros, em condições de intenso calor e baixa umidade relativa do ar.

\subsubsection{Nutrição Mineral}

KEEPER(1966) afirmou que o milho requer solos bem férteis, requerendo quantidades relativamente grandes de nitrogênio e potássio, sendo também um dos cereais mais exigentes em fósforo, embora a quantidade deste seja menor do que as de nitrogênio e potássio.

Grüneberg ${ }^{1}$ (1959), citado por MALAVOLTA \& GARGANTINI(1966),

1 GRÜNEBERG, F.H. Nutrición y fertilización del maiz. Verlagsgesellschaft für Ackerbau mbH..Hanover, 1959. Bol. Verde 9. 
afirmou que o milho suporta solos bastante ácidos, embora o $\mathrm{pH}$ ótimo esteja em torno de 6,0 a 7,0. Desenvolve-se bem em solos alcalinos, desde que não haja falta de micronutrientes.

IGNATIEFF \& PAGE(1958) afirmaram que uma tonelada de grãos de milho remove do solo: $27,9 \mathrm{~kg}$ de nitrogênio, $20,5 \mathrm{~kg}$ de potássio, $10,3 \mathrm{~kg}$ de fósforo, $1,6 \mathrm{~kg}$ de cálcio e $1,3 \mathrm{~kg}$ de enxofre .

RESENDE et al(1990) afirmaram que a extração de nutrientes varia com a produtividade. Os autores mostraram uma tabela de extração de nutrientes (Tabela 3) para diversas produtividades, observando que a adubação da cultura do milho deve basear-se na análise do solo, no histórico de uso da área e na produtividade esperada.

TABELA 3 - Extração de nutrientes $(\mathrm{Kg} / \mathrm{ha})$ pelo milho em diferentes níveis de produtividade

\begin{tabular}{cccc}
\hline Produtividade & $\mathrm{N}$ & $\mathrm{P}_{2} \mathrm{O}_{5}$ & $\mathrm{~K}_{2} \mathrm{O}$ \\
\hline 5.000 & 125 & 50 & $75-100$ \\
6.000 & 135 & 55 & $90-120$ \\
8.000 & 175 & 75 & 150 \\
9.500 & 187 & 85 & 230 \\
\hline
\end{tabular}

FONTE: ARNON(1975)

KEEPER(1966) observou que a necessidade dos elementos não é uniforme durante o período vegetativo. $\mathrm{O}$ milho apresenta uma pequena necessidade de nitrogênio no início desse período, uma demanda máxima durante 30 a 40 dias e uma pequena demanda no final. A necessidade de potássio distribui-se por uma maior faixa do período de crescimento. A necessidade de fósforo é pequena, porém contínua durante 
todo o período vegetativo do milho.

MALAVOLTA \& GARGANTINI(1966) deram um panorama geral da nutrição mineral da cultura do milho. Em termos de absorção de nutrientes, dividem-na èm absorção via solo e absorção foliar.

Os autores afirmam que o nitrogênio em forma de uréia provoca queimadura nas folhas, mesmo em soluções de concentração entre 1,0 e 1,5\%, devido às rápidas reações de hidrólise da uréia. Salientaram também que o volume de terra que as raízes do milho podem explorar e retirar nutrientes é grande. Por isso o adubo não deve ficar localizado apenas próximo à superficie. Observam também que a absorção do potássio é bem mais intensa do que a de nitrogênio e de fósforo no período que vai da emergência até o aparecimento da inflorescência masculina, havendo uma atenuação da absorção a partir daí.

A absorção de cálcio pelo milho é influenciada pelo ânion acompanhante. $\mathrm{O}$ nitrato, o fosfato, o carbonato e o sulfato facilitam-na mais que o cloreto. $\mathrm{O}$ elemento se concentra principalmente nas folhas mais velhas, sendo muito pequena a quantidade encontrada nos grãos.

O magnésio é um elemento encontrado em maior quantidade nas folhas. Quando a planta completa o seu ciclo, cerca de 33\% do magnésio absorvido pela planta encontra-se nos grãos. O milho é considerado uma espécie muito sensível à deficiência de magnésio. MALAVOLTA \& GARGANTINI(1966) estimaram que há uma concentração aproximada de $0,5 \%$ de magnésio nos grãos. 
Em relação ao enxofre a forma predominantemente absorvida pelo milho é o ânion sulfato. NELSON(1956) afirma que a absorção do sulfato é inversamente proporcional às concentrações de nitrato e de cálcio no substrato. Comparando as proporções de enxofre e fósforo no milho, nota-se que o primeiro é mais abundante na parte vegetativa e o segundo predomina na espiga.

Grüneberg $^{2}$ (1959), citado por MALAVOLTA \& GARGANTINI (1966), constatou, na Austrália, que a deficiência de molibdênio nas plantas de milho apresenta sintomas semelhantes aos da deficiência de nitrogênio. Isto se explica pelo conhecido papel desse micronutriente na redução dos nitratos.

Segundo VIETS JR. et al(1953), o milho está classificado entre as plantas com baixa capacidade de extrair zinco do solo. Deve-se fazer uma adubação com o elemento em distribuição a lanço e incorporação, na semeadura, ou em pulverizações foliares de sulfato de zinco a $0,3 \%$ durante a fase de crescimento.

DOURADO NETO et al.(1991) afirmaram que, para uma adubação eficiente, é necessário levar-se em consideração os seguintes aspectos relativos à planta: marcha de absorção de nutrientes ao longo do ciclo da cultura e quantidade extraída de nutrientes em função do rendimento da cultura.

Com relação à recomendação de adubação, os autores observaram que a recomendação deve ser feita em função do rendimento desejado, que é definido pela

${ }^{2}$ GRÜNEBERG, F.H. Nutrición y fertilización del maiz. Verlagsgesellschaft für Ackerbau mbH.. Hanover, 1959. Bol. Verde 9. 
demanda do mercado, e que a quantidade a aplicar é definida em função do máximo rendimento econômico e da extração de nutrientes para alcançar esse rendimento. Além disso, a quantidade a aplicar é dependente da capacidade de fornecimento da fase solo, que é variável, justificando experimentos com doses crescentes de fertilizantes oscilando em torno do valor geral fornecido pela pesquisa, em pequenas áreas adjacentes à de exploração comercial. Os autores também afirmaram que o parcelamento da adubação dependerá da quantidade total a aplicar, da concentração máxima recomendada do fertilizante na água de irrigação, da capacidade do tanque de solução fertilizante e da duração do período de máxima demanda do nutriente no ciclo da planta.

\subsection{Delineamento e Análise Estatística}

Vários autores tentaram contornar os problemas com a análise estatística aplicada ao sistema de aspersão em linha, pois este não permite a casualização total das parcelas experimentais, devido à impossibilidade de se variar a localização das lâminas de água. HANKS et al(1976), comenta que a adoção do "line source" gera uma limitação na análise estatística para efeito de tratamentos, pois os níveis de água não podem ser devidamente casualizados. A variação desses níveis é seqüencial e imposta pelo sistema de irrigação. $\mathrm{O}$ autor lembra, no entanto, que os efeitos da irrigação sobre a produção normalmente garantem evidências suficientes para impedir que as análises estatísticas tornem-se críticas.

FARIA(1981) utilizou métodos de estatística não paramétrica (teste de Friedman) e paramétrica (análise de variância para blocos ao acaso), obtendo os mesmos 
resultados em ambas as análises. BAUDER et al(1975) compararam um experimento devidamente casualizado a outro com restrição de casualização semelhante ao sistema de aspersão em linha, obtendo as mesmas conclusões em ambos os casos. Pode-se dizer que nem sempre a casualização é limitante. Os autores afirmaram que as vantagens da utilização do sistema de aspersão em linha justificam sua utilização.

O delineamento experimental a ser utilizado apresenta uma certa variação entre os autores consultados. FRIZZONE(1986), trabalhando com lâminas de água, adubação nitrogenada e funções de produção em feijoeiro, utilizou o delineamento em blocos ao acaso com parcelas subdivididas, ou "split-plot", com parcelas dispostas em direção perpendicular à linha de aspersores. MENEZES(1990), estudando a produção de sementes de cebola, utilizou o delineamento em blocos casualizados. CALHEIROS (1990), fazendo estudos sobre lâminas de irrigação, níveis de nitrogênio e produção de cana-de-açúcar, utilizou o delineamento em blocos ao acaso com tratamentos dispostos em faixas ("strip-block").

Em todos os casos citados, a análise dos resultados foi feita através de métodos de estatística paramétrica. Os autores analisaram os resultados através de regressões polinomiais, utilizando os componentes linear e quadrático, de acordo com o que afirmam CAMPOS(1967) e LOUSADA \& COUTO (1983). 


\section{MATERIAL E MÉTODOS}

\section{1. Área experimental}

O experimento foi instalado em uma área experimental do Departamento de Engenharia Rural, no campus da Escola Superior de Agricultura "Luiz de Queiroz", localizada no município de Piracicaba, na latitude $22^{\circ} 42^{\prime} 30^{\prime \prime} \mathrm{S}$, longitude $47^{\circ} 38^{\prime} 00^{\prime \prime} \mathrm{W}$ e altitude de $546 \mathrm{~m}$.

\subsection{Caracterização do solo e controle da irrigação}

O solo do local do experimento é classificado como Terra Roxa Estruturada série Luiz de Queiroz, segundo RANZANI et al(1966). Pelo sistema norteamericano de classificação, o solo é do tipo Paleudalf óxico (USDA, 1976), originado de rochas eruptivas básicas, com perfil homogêneo e muito profundo e lençol freático a vários metros abaixo da superficie.

A caracterização fisica do solo é dada por MOURA(1992), que apresentou sua análise granulométrica. O solo é formado por cerca de $65 \%$ de argila, 
$15 \%$ de silte e $20 \%$ de areia, densidade global de $1,4 \mathrm{~g} / \mathrm{cm}^{3}$ e velocidade de infiltração básica de $12 \mathrm{~mm} / \mathrm{h}$, sendo classificado como muito argiloso. A Tabela 4 apresenta os parâmetros da equação de VAN GENUCHTEN(1980), que relaciona a umidade atual do solo com a tensão da água no mesmo. A equação de Van Genuchten é apresentada a seguir:

$$
\theta \mathrm{a}=\theta \mathrm{r}+\frac{\theta \mathrm{s}-\theta \mathrm{r}}{\left[1+(\alpha \cdot|\Psi \mathrm{m}|)^{\mathrm{n}}\right]^{\mathrm{m}}}
$$

onde:

$$
\begin{aligned}
& \mathrm{h}=\text { valor absoluto do potencial matricial }\left(\left|\Psi_{\mathrm{m}}\right|\right)(\text { m.c.a. }) \\
& \theta \mathrm{a}=\text { umidade atual }\left(\mathrm{cm}^{3} / \mathrm{cm}^{3}\right) \\
& \theta \mathrm{r}=\text { umidade residual }\left(\mathrm{cm}^{3} / \mathrm{cm}^{3}\right) \\
& \theta \mathrm{s}=\text { umidade de saturação }\left(\mathrm{cm}^{3} / \mathrm{cm}^{3}\right)
\end{aligned}
$$

TABELA 4 - Parâmetros de ajuste da curva de retenção de água no solo à equação de Van Genuchten

\begin{tabular}{ccccccc}
\hline $\begin{array}{c}\text { Profundidade } \\
(\mathrm{cm})\end{array}$ & $\mathrm{a}$ & $\mathrm{m}$ & $\mathrm{n}$ & $\theta_{\mathrm{r}}$ & $\theta_{\mathrm{S}}$ & c.a. \\
\cline { 5 - 7 } & & & & & $\left(\mathrm{cm}^{3} / \mathrm{cm}^{3}\right)$ & \\
\hline $0-10$ & 0,2268 & 0,2375 & 1,3116 & 0,204 & 0,482 & 0,978 \\
$10-20$ & 0,2722 & 0,2107 & 1,2669 & 0,213 & 0,453 & 0,967 \\
$20-30$ & 0,1460 & 0,2012 & 1,2520 & 0,244 & 0,449 & 0,935 \\
$30-40$ & 0,1743 & 0,2049 & 1,2578 & 0,271 & 0,502 & 0,944 \\
\hline
\end{tabular}

* c.a. : coeficiente de ajuste

FONTE: MOURA(1992)

O controle da irrigação foi feito através de tensiômetros, com aferição 
pelo tanque Classe A. Os tensiômetros foram instalados na área experimental, em quatro baterias de dois tensiômetros, à profundidade de 15 e $30 \mathrm{~cm}$.

O tanque Classe $\mathrm{A}$ que forneceu as leituras está localizado no posto meteorológico da Escola Superior de Agricultura "Luiz de Queiroz", cerca de dois mil metros de distância da área experimental. A leitura de ambos foi feita diariamente.

O momento de irrigar foi determinado através da medição da tensão da água no solo, utilizando tensiômetros na área experimental. A cultura foi irrigada sempre que o potencial matricial da água no solo chegou à faixa de $-50,66 \mathrm{a}-81,06 \mathrm{kPa}(-0,5 \mathrm{a}-$ 0,8 atm.).

A equação de Van Genuchten foi utilizada para determinar a lâmina de água a aplicar em cada irrigação. Conhecendo-se a tensão da água no solo, aplica-se essa equação para determinar a umidade volumétrica $(\mathrm{cm} 3 \mathrm{H} 2 \mathrm{O} / \mathrm{cm} 3$ solo). Estabelecendose os níveis mínimo e máximo de umidade volumétrica em cada camada, determina-se a lâmina de água disponível no solo através da equação:

$$
\mathrm{h} \mathrm{d}=(\theta c c-\theta \text { crít } .) \cdot \mathbf{z}
$$

onde:

$\mathrm{h}_{\mathrm{d}}$ = lâmina máxima de água disponível $(\mathrm{mm})$;

$\theta_{\mathrm{cc}}=$ umidade volumétrica máxima, denominada capacidade de campo $\left(\mathrm{cm}^{3} / \mathrm{cm}^{3}\right)$;

$\theta_{\text {crit. }}=$ umidade volumétrica mínima, denominada umidade crítica $\left(\mathrm{cm}^{3} / \mathrm{cm}^{3}\right)$;

$\mathrm{z} \quad$ = profundidade da camada de solo $(\mathrm{mm})$ 
A lâmina de água reposta através de irrigações foi calculada através da seguinte equação:

onde:

$$
\mathrm{h}_{\mathrm{i}}=\frac{(\theta \mathrm{cc}-\theta \mathrm{a}) \cdot \mathrm{z}}{\mathrm{E} \mathrm{i}}
$$

$$
\begin{aligned}
& \mathrm{h}_{\mathrm{i}}=\text { lâmina de água reposta pela irrigação }(\mathrm{mm}) ; \\
& \theta_{\mathrm{a}}=\text { umidade atual do solo }\left(\mathrm{cm}^{3} / \mathrm{cm}^{3}\right) ; \\
& \mathrm{E}_{\mathrm{i}}=\text { eficiência de irrigação }
\end{aligned}
$$

A análise química do solo, feita pelo laboratório do Departamento de Solos Geologia e Fertilizantes, da Escola Superior de Agricultura 'Luiz de Queiroz", é apresentada na Tabela 5. Juntamente com os seus resultados apresenta-se recomendação de adubação do laboratório, para produção de quatro a seis toneladas de grãos de milho por hectare (Tabela 6).

TABELA 5 - Resultados da análise de solo

\begin{tabular}{cccccccccc}
\hline $\mathrm{pH}$ & $\mathrm{M} .0$. & $\mathrm{P}$ & $\mathrm{K}$ & $\mathrm{Ca}$ & $\mathrm{Mg}$ & $\mathrm{H}+\mathrm{Al}$ & $\mathrm{SB}$ & $\mathrm{T}$ & $\mathrm{V}$ \\
\cline { 3 - 9 } $\mathrm{CaCl} 2$ & $\%$ & $\mathrm{mg} / \mathrm{cm}^{3}$ & & & $\mathrm{meq} / 100 \mathrm{~cm}^{3}$ & & & $\%$ \\
\hline $5,0 \mathrm{~B}$ & 1,7 & $6 \mathrm{MB}$ & $0,43 \mathrm{~A}$ & 4,9 & $1,5 \mathrm{~A}$ & 2,5 & 6,8 & 9,3 & $73 \mathrm{~A}$ \\
\hline Obs.: & $\mathrm{MB}=$ muito baixo & $\mathrm{B}=$ baixo & $\mathrm{M}=$ médio & $\mathrm{A}=$ alto & $\mathrm{MA}=$ muito alto &
\end{tabular}

TABELA 6 - Recomendações técnicas para adubação de plantio

\begin{tabular}{ccccccccc}
\hline Cultura & Calcário & \multicolumn{9}{c}{ Adubação de Plantio } & Unidade \\
\cline { 3 - 8 } & t/ha & $\mathrm{N}$ & $\mathrm{P}_{2} \mathrm{O}_{5}$ & $\mathrm{~K}_{2} \mathrm{O}$ & $\mathrm{S}^{*}$ & $\mathrm{~B}$ & $\mathrm{Zn}$ & \\
\hline Milho & 0,0 & 15 & 80 & 20 & 30 & -- & 4,0 & (kg/ha) \\
\hline
\end{tabular}

* Aplicar somente se a formulação NPK não contiver o elemento em quantidade suficiente 


\subsection{Cultura e tratos culturais}

A cultura utilizada foi o milho (Zea mays L.), cultivar AG-303 (híbrido duplo de ciclo precoce). Essa cultura foi escolhida por sua grande importância econômica, expressiva área cultivada e alta sensibilidade à adubação nitrogenada.

O preparo da área experimental foi feito utilizando-se trator e implementos. Foram feitas a aração e a gradagem da área, utilizando-se arado de discos e grade aradora, respectivamente. Foram abertos pequenos sulcos para o plantio das sementes, utilizando-se trator e um sulcador.

A semeadura foi feita manualmente, nos dias 21 e 22/10/1993. Antes da semeadura foi feita uma irrigação, para que o solo atingisse a capacidade de campo. Considerou-se como capacidade de campo a umidade em que o potencial matricial da água no solo atingiu - 5,07 $\mathrm{kPa}(0,05 \mathrm{~atm})$. A adubação de plantio seguiu a análise de solo e a recomendação de adubação feitas pelo laboratório do Departamento de Química da Escola Superior de Agricultura "Luiz de Queiroz". Aplicou-se $23 \mathrm{~kg} \mathrm{~N} / \mathrm{ha}, 80 \mathrm{~kg}$ $\mathrm{P}_{2} \mathrm{O} 5$ /ha e $46 \mathrm{~kg} \mathrm{~K} \mathrm{O} / \mathrm{ha}$ (formulação NPK 04-14-08). A emergência das plântulas ocorreu no dia 25/10/1993.

Quinze dias após a germinação(10/11/93) foi feito um desbaste para atingir a população desejada (60.000 plantas por hectare), segundo recomendações técnicas da cultivar para áreas irrigadas.

Durante o ciclo da cultura também foi necessário eliminar as plantas daninhas através de controle mecânico e químico. $\mathrm{O}$ controle mecânico foi realizado aos 
seis e quatorze dias após a germinação (31/10 e 9/11/1993), através de capinas manuais. O controle químico foi feito aos vinte e quatro dias após a germinação (19/11/1993), utilizando o herbicida Gramoxone.

Foi preciso fazer o controle químico de saúvas (Atta sp.), no dia da emergência. Os ataques de lagarta-rosca (Agrotis ypsilon) e lagarta-do-cartucho (Spodoptera frugiperda), apesar de ocorrerem, não provocaram danos significativos à cultura.

A colheita foi feita manualmente, aos 127 dias após a germinação (01/03/94), coletando-se as espigas da área útil da parcela experimental. Na fase de armazenamento da produção para análise de resultados, foi feito um controle químico de carunchos.

\subsection{Delineamento experimental}

A área experimental foi dividida em quatro blocos, dispostos paralelamente às curvas em nivel do terreno. Houve oito tratamentos em cada bloco, dispostos em direção perpendicular às linhas de aspersores, perfazendo um total de trinta e duas parcelas, conforme mostra a Figura 1.

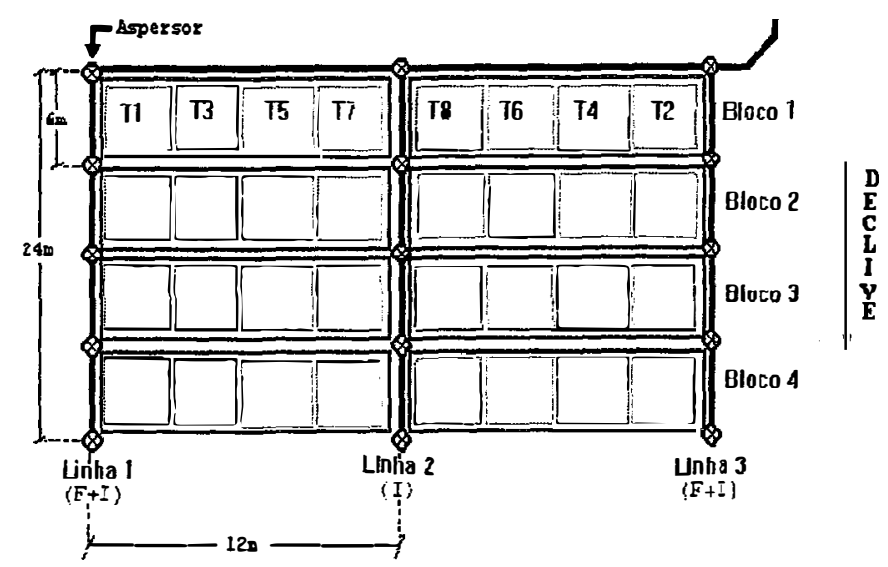

Figura 1 - Área experimental e equipamento de irrigação 
As parcelas experimentais tiveram três metros de comprimento e seis metros de largura $\left(18 \mathrm{~m}^{2}\right)$, conforme mostra a Figura 2. A área útil de cada parcela foi de $8 \mathrm{~m}^{2}(2,0 \times 4,0 \mathrm{~m})$.

Barcela Experimental

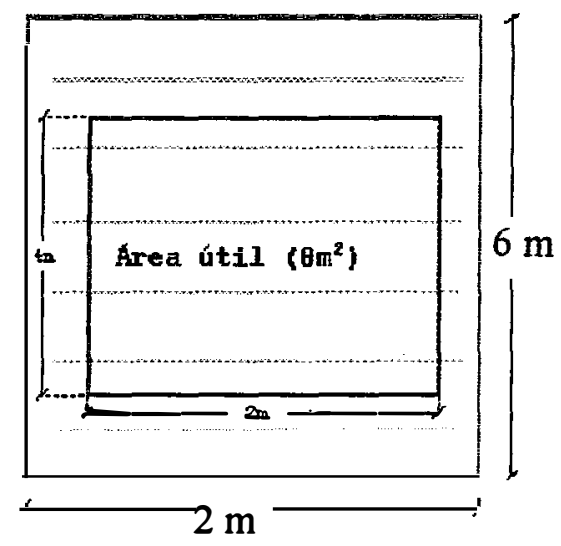

Figura 2 - Parcela experimental e área útil da parcela

\subsection{Equipamento de irrigação e aplicação do fertilizante}

A distribuição de água do aspersor utilizado determina a distribuição do fertilizante, nas linhas utilizadas para a fertirrigação. Desta forma, obteve-se diferentes doses de fertilizante de acordo com a distância em relação às linhas de aspersores. No experimento houve três linhas de aspersores, sendo que as externas foram utilizadas para fertirrigação e irrigação, enquanto que a linha do meio foi utilizada apenas para irrigação, conforme mostra a Figura 3.

Os aspersores utilizados foram da marca Dantas, modelo MD20A, com bocal único de $3,1 \mathrm{~mm}$. A vazão, medida em laboratório e no campo, foi de $0,6 \mathrm{~m}^{3} / \mathrm{h}$ à pressão de $294,21 \mathrm{kPa}\left(3,0 \mathrm{kgf} / \mathrm{cm}^{2}\right)$. No espaçamento utilizado $(6 \times 12 \mathrm{~m})$ a lâmina aplicada foi de $7,5 \mathrm{~mm} / \mathrm{h}$, considerando-se uma eficiência de aplicação de $90 \%$. 
adotado originou-se de ensaios de distribuição de precipitação feitos no laboratório de irrigação do Departamento de Engenharia Rural, da Escola Superior de Agricultura "Luiz de Queiroz", e de simulações feitas por computador.

A aplicação do fertilizante foi feita através de um tanque de derivação, conforme mostra a Figura 4 . Um registro de gaveta na tubulação proporcionou a diferença de pressão necessária para que a água passasse pela tubulação de entrada do tanque, saindo pela outra tubulação e levando o fertilizante contido no tanque até os aspersores, que o distribuíram na área experimental.

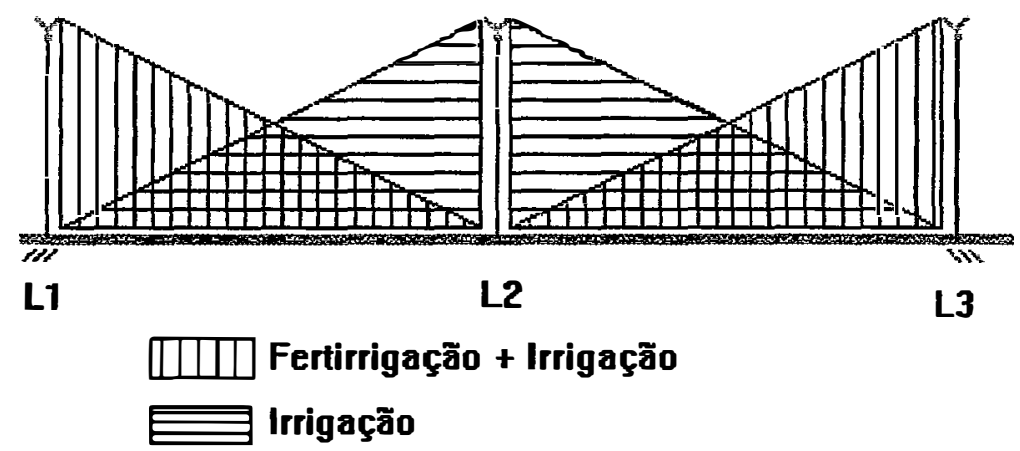

Figura 3 - Perfil de distribuição de água e fertilizante

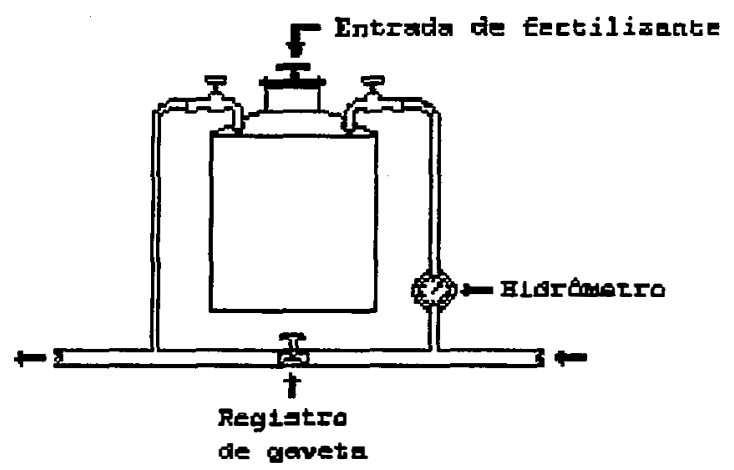

Figura 4 - Tanque de aplicação de fertilizantes 
A aplicação do fertilizante (uréia) foi feita de forma parcelada, em quatro épocas, determinados de acordo com o estágio fenológico da cultura: a) plantas com 7-8 folhas (23 d.a.g.); b) plantas com 10-11 folhas (34 d.a.g.); c) plantas com 13-14 folhas (42 d.a.g.); d) plantas com 15-16 folhas (49 d.a.g.).

As doses de uréia aplicadas em cada época foram iguais em uma mesma linha de aspersores utilizada para fertirrigação. $O$ tanque de derivação recebeu $3,5 \mathrm{~kg}$ de uréia, em cada aplicação feita pela linha 1, e 3,0 kg de uréia, nas aplicações feitas pela linha 3. Para a aplicação de fertilizantes de forma diferenciada, conectou-se apenas uma linha de fertirrigação de cada vez. Para manter a lâmina de água homogênea em toda a área, aplicou-se água através da linha central por um espaço de tempo igual ao utilizado para a fertirrigação.

O aparecimento da inflorescência masculina ocorreu cinco dias após a última aplicação de fertilizante (54 d.a.g.).

A concentração do fertilizante no tanque vai diminuindo à medida em que a água da tubulação passa pelo tanque. Esse comportamento é explicado pela seguinte equação (FRIZZONE, 1993):

$$
C_{t}=C_{0} \cdot e^{-x}
$$

onde:

$C_{t}=$ concentração de fertilizante no tanque, num determinado tempo $t$

$\mathrm{C}_{0}=$ concentração inicial de fertilizante no tanque $(\mathrm{t}=0)$

$\mathrm{x}=$ relação entre $\mathrm{o}$ volume que passou pelo tanque $(\mathrm{V})$ até o tempo $\mathrm{t} e \mathrm{o}$ volume do tanque $(\mathrm{Vt})$ 
Pode-se trabalhar com concentrações relativas, facilitando 0 entendimento. Assim, a equação modificada será:

$$
C_{t}=100 \cdot e^{-x}
$$

onde:

$$
\mathrm{C}_{\mathrm{t}}=\text { concentração (\%) num determinado tempo (t) }
$$

É desejável que todo o fertilizante seja aplicado e, portanto, a concentração final de fertilizante no tanque não deve ultrapassar a $2 \%$ da concentração inicial.

Para este experimento, estipulou-se uma concentração mínima de $0,1 \%$ da concentração inicial. Isto implicou em um volume de passagem de água igual a 6,9 vezes o volume do tanque $(x=6,9)$. No caso deste experimento, foi usado um tanque de 55 litros e a vazão derivada ao mesmo foi da ordem de $381 / \mathrm{min}$ (medida através de um hidrômetro), o que nos dá um tempo de aplicação de fertilizante de 10 minutos, aproximadamente. Após cada fertirrigação, o sistema ainda funcionou por mais 10 minutos, proporcionando uma lavagem das folhas da cultura. A lâmina de água aplicada durante cada fertirrigação foi de $2,5 \mathrm{~mm}$ (fertirrigação e lavagem de folhas).

$\mathrm{O}$ fertilizante utilizado foi a uréia $(45 \% \mathrm{~N})$, devido à sua grande utilização, sua elevada concentração de nitrogênio e sua boa solubilidade em água. As doses de fertilizante em cada tratamento foram determinadas através da lâmina de água coletada por uma linha de recipientes com diâmetro médio de 103,1 milímetros, espaçados de dois metros entre si, conforme mostra a Figura 5. Esses recipientes foram reinstalados acima do nível da cultura, nas últimas duas aplicações, devido à interferência que causam as folhas da cultura na lâmina de água coletada. 


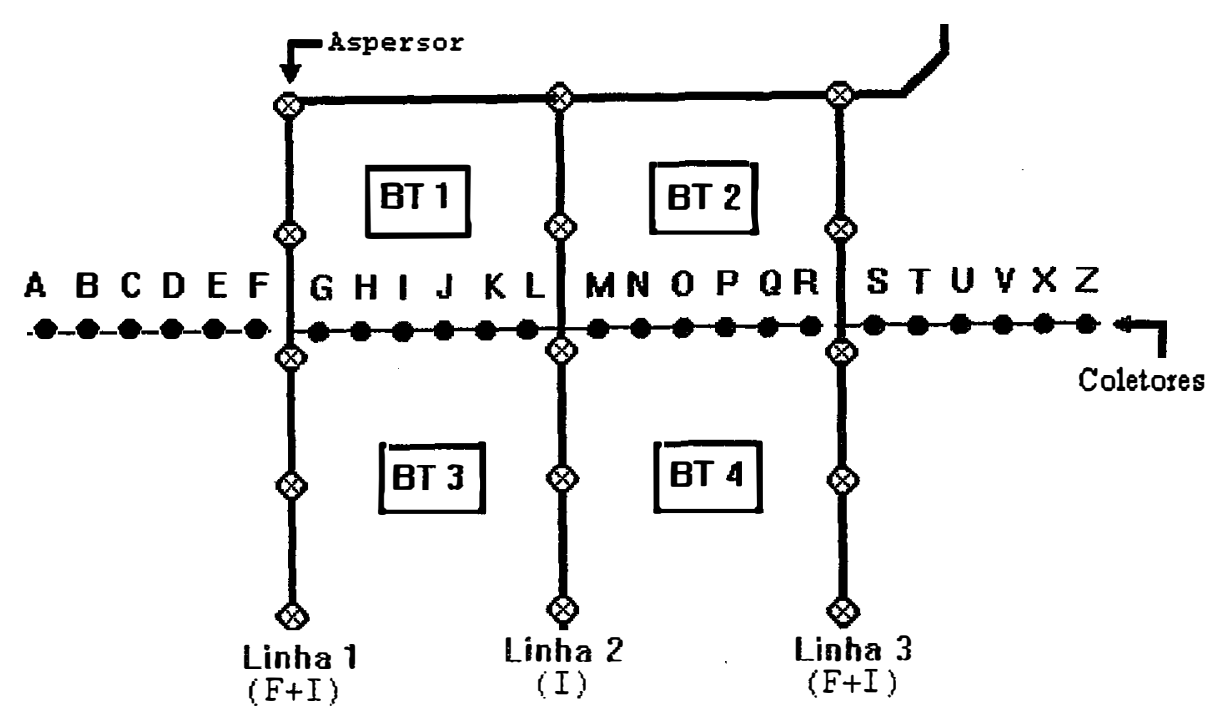

BT : bateria de tensiômetros

Figura 5 - Distribuição de coletores na área experimental

\subsection{Análise dos resultados}

A análise dos resultados foi feita baseando-se em parâmetros vegetativos e produtivos da cultura do milho. Visando a verificação de possíveis diferenças entre os tratamentos de fertirrigação.

\subsubsection{População final de plantas}

A população final de plantas em cada bloco foi analisada para verificar possíveis diferenças que pudessem afetar a análise do experimento. Foi determinada através da média da população de plantas em cada tratamento, obtida através da contagem de três fileiras de plantas, perfazendo um total de nove metros lineares por tratamento. 


\subsubsection{Altura das plantas}

Foram escolhidas e marcadas três plantas em cada tratamento, para as medições ao longo do ciclo da cultura. Mediu-se a altura de plantas em três fases do ciclo, com o auxílio de uma trena:

- $\quad$ plantas com 7 a 8 folhas (23 d.a.g.);

- $\quad$ plantas com inflorescência masculina (53 d.a.g.);

- plantas com espigas .

$\mathrm{Na}$ fase vegetativa, mediu-se a altura das plantas até a última folha desenrolada. A partir da fase reprodutiva, mediu-se a altura de plantas até a inserção da última folha.

\subsubsection{Altura de espigas nas plantas}

Juntamente à última medição de altura de plantas, foi feita a medição da altura das espigas nas plantas em cada tratamento. A altura de inserção das espigas foi feita da mesma forma que nas medições de altura de plantas, e também nas mesmas plantas.

\subsubsection{Produtividade}

A produtividade foi determinada através da pesagem da produção colhida na área útil de cada parcela experimental $\left(8 \mathrm{~m}^{2}\right)$. Contou-se também o número de plantas dentro da área útil para determinar a produção por planta e para corrigir possíveis diferenças de produtividade devidas a falhas nas parcelas. Esta correção foi feita através 
da fórmula citada por TAVARES(1972):

$$
\text { P.c. }=\frac{\text { P.o. }+(P . i .-0,30 \times F)}{\text { P.i. }-F}
$$

onde:

P.c. : Produtividade corrigida para população ideal (kg/ha);

P.o. : Produtividade observada em parcelas que apresentaram falhas (kg/ha);

P. I. : População ideal de plantas por parcela (no caso, $60 \mathrm{pl} . / \mathrm{ha}$, ou 48pl./parcela);

F : Número de falhas na parcela.

A utilização desta fórmula parte do pressuposto que $70 \%$ do potencial de produção das plantas perdidas é recuperado pelas plantas vizinhas às falhas, pela maior luminosidade e menor competição por água e nutrientes.

Também foi feita a correção da umidade do material colhido para a umidade padrão (13\%), de forma semelhante àquela feita para o peso de mil grãos, mas com a diferença da unidade de medida (neste caso, produtividade em $\mathrm{kg} / \mathrm{ha}$ ).

\subsubsection{Comprimento de espigas e grãos}

Foram medidos o comprimento e o diâmetro das espigas, e também o diâmetro dos sabugos, para a verificação da influência dos tratamentos no comprimento das espigas e dos grãos. $\mathrm{O}$ comprimento dos grãos foi determinado através da diferença entre os diâmetros das espigas e dos sabugos. As medições foram feitas com o auxílio de um paquímetro. Foram medidas dez espigas e seus respectivos sabugos, o que 
correspondeu a aproximadamente $20 \%$ do total de espigas de cada tratamento.

\subsubsection{Peso de mil grãos}

O peso de mil grãos foi determinado utilizando-se metodologia adaptada do laboratório de sementes do Departamento de Agricultura da Escola Superior de Agricultura “Luiz de Queiroz". Foram retiradas e pesadas quatro amostras de 100 grãos em cada tratamento, calculando-se o desvio padrão, o peso médio e o coeficiente de variação de cada grupo de amostras. $\mathrm{O}$ grupo foi considerado homogêneo sempre que o coeficiente de variação foi inferior a $6 \%$. A partir daí, tomou-se a média de peso de 100 grãos de cada tratamento e multiplicou-se por 10, para obter o peso de 1000 grãos. Esse peso foi corrigido para a umidade padrão de $13 \%$, através da equação:

$$
\text { P.g.c. }=\frac{\text { P.g.o. } x(100-U \%)}{100-U P \%}
$$

onde:

P.g.c. : peso de grãos corrigido(g);

P.g.o. : peso de grãos observado(g);

U\% : Umidade observada na amostra;

UP\% : Umidade padrão (no caso, 13\%);

\subsubsection{Teor de nitrogênio dos grãos}

A quantidade de nitrogênio presente nos grãos de milho influencia sua qualidade nutricional. Logo, uma variação do teor de nutrientes pode determinar a quantidade de grãos a ser utilizada, seja no consumo in natura ou de produtos industrializados.

O teor de nitrogênio dos grãos foi determinado através de análises feitas 
pelo laboratório do Departamento de Química da Escola Superior de Agricultura "Luiz de Queiroz”.

\subsubsection{Função de produção para o fator dose de nitrogênio}

Para a obtenção da função de produção foi necessária uma etapa prévia. O perfil de distribuição do fertilizante na área experimental foi contínuo e decrescente no sentido transversal às linhas de aspersores (vide Figura 3). Por isso, para se obter a dose média aplicada em cada tratamento, foram ajustadas funções para estimar a dose de nitrogênio em relação à distância da linha de fertirrigação. Utilizando-se um método de integração definida, obtém-se a área abaixo de cada trecho desejado, que representa o total aplicado naquele trecho. No caso, utilizou-se intervalos de 3 metros (comprimento das parcelas). A dose média aplicada em cada parcela foi obtida dividindo-se o total aplicado pelo comprimento da parcela $(3 \mathrm{~m})$.

Os resultados utilizados para esta tarefa foram obtidos através da disposição de uma linha de coletores espaçados de dois metros entre si, em sentido transversal à linha de fertirrigação (vide Figura 5).

Conhecendo-se a concentração de nitrogênio no fertilizante, a quantidade de fertilizante que saiu do tanque para a área experimental e a vazão do equipamento de irrigação e o tempo de aplicação de fertilizante e lavagem de folhas, pode-se calcular a concentração de nitrogênio na água utilizada para fertirrigação. Essa concentração multiplicada pelo volume de água presente em cada coletor é a dose de adubo aplicada em cada posição.

Este procedimento foi feito para a linha 1 e para a linha 3 , pois a 
fertirrigação foi feita com doses diferentes em cada linha (o tanque de derivação recebeu $3,5 \mathrm{~kg}$ de uréia para a linha 1 e $3,0 \mathrm{~kg}$ para a linha 3 ).

Após a obtenção da dose média de fertilizante e da produtividade em cada tratamento, foi determinada a função de produção do milho em relação à dose de nitrogênio. Conforme a função obtida, pôde-se verificar qual foi a dose do nutriente que proporcionou a máxima produtividade.

Foi feito um estudo dos modelos mais adequados para a representação dos resultados obtidos. Através da literatura consultada (PEREIRA \& ARRUDA, 1987), pôde-se perceber que os principais modelos matemáticos utilizados para a estimativa de funções de produção de produtos agrícolas são:

a) modelo quadrático:

$$
Y=a_{0}+a_{1} \cdot x+a_{2} \cdot x^{2}
$$

b) modelo exponencial quadrático:

$$
\mathrm{Y}=\mathrm{e}^{\left(\mathrm{a} 0+\mathrm{a} 1 \cdot \mathrm{x}+\mathrm{a} 2 \cdot \mathrm{x}^{2}\right)}
$$

c) modelo raiz quadrada:

onde:

$$
Y=a_{0}+a_{1} \cdot \sqrt{x}+a_{2} \cdot x^{2}
$$

Y : produção de grãos estimada pelo modelo $(\mathrm{kg} / \mathrm{ha})$;

$\mathrm{x}$ : dose de nitrogênio $(\mathrm{kg} / \mathrm{ha})$;

a0, a1 e a2 : parâmetros obtidos através de regressão para cada um dos modelos

A partir dos modelos disponíveis e com o auxílio de um "software" computacional específico (STATGRAPHICS), foram estimados os parâmetros da regressão para cada um dos modelos. Escolheu-se o modelo que melhor representou os resultados obtidos. 


\section{4 . RESULTADOS E DISCUSSÃO}

\subsection{População final de plantas}

A população final de plantas foi analisada(Ver Tabela 7) e não foram constatadas diferenças significativas entre os tratamentos (Teste F a 5\%). Isto permitiu a análise dos resultados considerando-se uma competição homogênea entre as plantas na área experimental. Apesar disso, foram feitas correções da população de plantas nas parcelas para determinação da produtividade em níveis populacionais padronizados (60.000 plantas por ha).

TABELA 7 - População final do experimento (pl./ha)

\begin{tabular}{c|cccc|c}
\hline \multirow{2}{*}{ Tratamentos } & \multicolumn{4}{|c|}{ Blocos } & \multirow{2}{*}{ Média * } \\
\cline { 2 - 5 } & 1 & 2 & 3 & 4 & \\
\hline N1 & 57667 & 54333 & 52000 & 54333 & 54583 \\
N2 & 59000 & 55667 & 52000 & 59000 & 56417 \\
N3 & 64333 & 61333 & 61000 & 55667 & 60583 \\
N4 & 61000 & 49000 & 55667 & 65667 & 57834 \\
N5 & 58000 & 58000 & 56667 & 56667 & 57334 \\
N6 & 56667 & 49000 & 63000 & 61000 & 57417 \\
N7 & 53333 & 58000 & 60000 & 58667 & 57500 \\
N8 & 50000 & 59000 & 56667 & 54333 & 55000 \\
\hline
\end{tabular}

* Os resultados do teste $\mathrm{F}$ não indicaram diferenças significativas entre médias 


\subsection{Altura das plantas}

A Tabela 8 e a Figura 6 mostram a evolução da altura das plantas ao longo do ciclo, nas três épocas de medição pré-definidas.

TABELA 8 - Evolução da média da altura das plantas $(\mathrm{m})$ ao longo do tempo

\begin{tabular}{cccccccccc}
\hline Tratamentos & 23 & Alt. & Teste & 54 & Alt. & Teste & 80 & Alt. & Teste* \\
& D.A.G. & Relat. & Tukey & D.A.G. & Relat. & Tukey & D.A. & Relat. & Tukey \\
\hline N1 & 0,53 & 21,77 & a & 2,15 & 88,09 & ab & 2,44 & 100,0 & a \\
N2 & 0,61 & 25,65 & a & 2,35 & 98,53 & a & 2,39 & 100,0 & ab \\
N3 & 0,50 & 21,57 & a & 2,02 & 87,91 & bc & 2,30 & 100,0 & abc \\
N4 & 0,61 & 26,85 & a & 2,00 & 88,40 & bc & 2,26 & 100,0 & abc \\
N5 & 0,48 & 21,61 & a & 1,95 & 87,35 & bc & 2,23 & 100,0 & abc \\
N6 & 0,55 & 25,17 & a & 1,89 & 86,78 & bc & 2,18 & 100,0 & bc \\
N7 & 0,50 & 22,84 & a & 1,77 & 81,55 & c & 2,17 & 100,0 & bc \\
N8 & 0,52 & 24,42 & a & 1,75 & 81,89 & c & 2,14 & 100,0 & c \\
\hline
\end{tabular}

* Teste de Tukey ao nível de $5 \%$ de significância. Letras diferentes indicam diferenças significativas entre tratamentos

Não se detectou diferenças significativas utilizando-se o teste de Tukey, ao nível de 5\% de significância, na primeira medição de altura (7-8 folhas, 23 d.a.g.).

A primeira aplicação de fertilizante via fertirrigação foi feita no dia da primeira medição, mostrando que a área experimental apresentou-se bastante homogênea nesse momento. As observações seguintes foram de fundamental importância para a explicitação do efeito da adubação nitrogenada de cobertura na cultura do milho. 


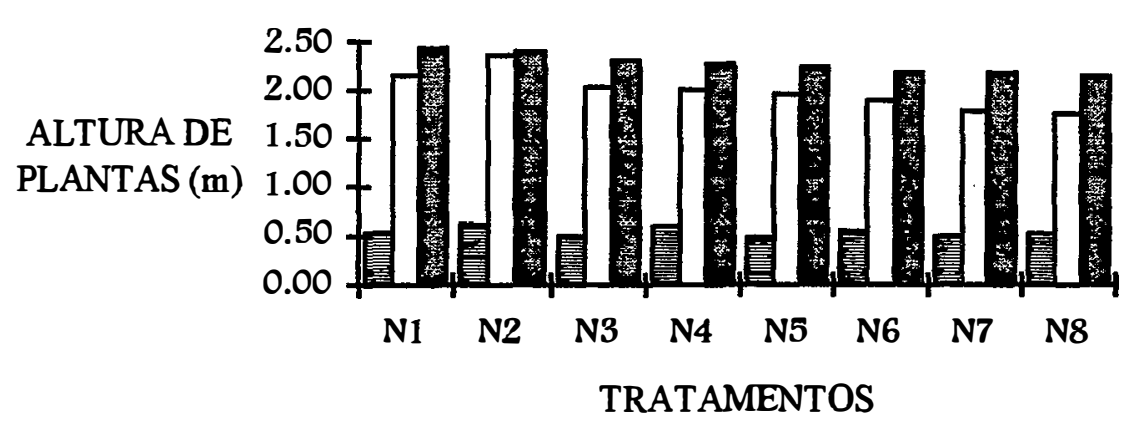

国23 D.A.G. $\square 54$ D.A.G. 80 D.A.G

Figura 6 - Evolução da altura de plantas ao longo do ciclo

A partir da segunda medição das plantas (54 d.a.g., plantas com inflorescência masculina), o teste de Tukey indicou diferenças significativas para as médias dos tratamentos (nível de 5\% de significância). Os tratamentos N1 e N2 foram superiores aos tratamentos $\mathrm{N} 7$ e $\mathrm{N} 8$, enquanto o tratamento $\mathrm{N} 2$ diferiu de todos os demais, exceto de N1.

Nesse período do experimento já se havia aplicado todo o fertilizante nitrogenado (Aplicações feitas em quatro partes iguais, aos 23 d.a.g. , 34 d.a.g., 42 d.a.g. e 49 d.a.g.). Já se nota um efeito das doses de nitrogênio na cultura, mostrando a sua importância para o crescimento e o acúmulo de substâncias de reserva. A época da segunda medição de altura das plantas marcou justamente o fim do período vegetativo e o início do período reprodutivo.

$\mathrm{Na}$ terceira medição das plantas, os tratamentos $\mathrm{N} 1, \mathrm{~N} 2, \mathrm{~N} 3$ e N4 diferiram de N8, pelo teste de Tukey, ao nível de 5\% de significância. $\mathrm{O}$ tratamento N1 foi superior aos demais. 
A adubação nitrogenada de cobertura influenciou a altura das plantas, sendo que, ao final do ciclo, essa altura foi menor à medida que se diminuiu a dose de nitrogênio aplicada. É reconhecida a influência do nitrogênio no crescimento e na produção de matéria seca nas plantas.

A última aplicação de nitrogênio foi feita aos 49 d.a.g., ou seja, 5 dias antes da segunda medição. $O$ nitrogênio proveniente da última fertirrigação provavelmente foi utilizado apenas para o acúmulo de matéria seca nos grãos. Com o final da fase vegetativa a planta começa a utilizar os nutrientes absorvidos e a transferir substâncias de reserva para os grãos. Esta afirmação é confirmada pelos resultados da Tabela 8 e da Figura 6. Percebe-se um crescimento vegetativo maior entre as duas primeiras medições.

\subsection{Altura de inserção das espigas nas plantas}

A altura da inserção das espigas nas plantas foi medida, constatando-se diferenças significativas entre os tratamentos, conforme mostra a Tabela 9. O tratamento N8 foi inferior aos demais, pelo teste de Tukey ao nível de 5\% de significância. Os quatro primeiros tratamentos (N1 a N4) não diferiram entre si, mas os dois primeiros(N1 e N2) diferiram dos tratamentos N5 a N8. 
TABELA 9 - Altura de inserção das espigas nas plantas (m)

\begin{tabular}{c|cccc|cc}
\hline \multirow{2}{*}{ Tratamentos } & \multicolumn{5}{|c|}{ Blocos } & \multirow{2}{*}{ Média * } \\
\cline { 2 - 5 } & 1 & 2 & 3 & 4 & & \\
\hline N1 & 1,46 & 1,46 & 1,48 & 1,40 & 1,45 & a \\
N2 & 1,53 & 1,50 & 1,46 & 1,26 & 1,44 & a \\
N3 & 1,30 & 1,36 & 1,29 & 1,32 & 1,32 & a b c \\
N4 & 1,44 & 1,37 & 1,31 & 1,23 & 1,34 & a b \\
N5 & 1,35 & 1,22 & 1,38 & 1,24 & 1,30 & b c \\
N6 & 1,19 & 1,24 & 1,34 & 1,17 & 1,24 & b c \\
N7 & 1,30 & 1,23 & 1,35 & 1,15 & 1,26 & b c \\
N8 & 1,20 & 1,23 & 1,27 & 1,08 & 1,20 & c \\
\hline
\end{tabular}

* Teste de Tukey a 5\% . Letras diferentes indicam diferenças significativas entre médias

\subsection{Produtividade}

Observou-se quatro grupos de resultados que diferiram significativamente entre si, pelo teste de Tukey ao nível de $5 \%$ de significância, conforme mostra a Tabela 10. São eles, em ordem decrescente:
a) N2 ( 262,59 Kg N/ha; 8041,05 Kg grãos/ha);
b) N1(319,47 Kg N/ha; $6237,81 \mathrm{Kg} / \mathrm{ha}), \mathrm{N} 4(149,84 \mathrm{Kg} \mathrm{N} / \mathrm{ha} ; 6071,16 \mathrm{Kg} / \mathrm{ha})$ e N3(176,38 Kg N/ha; 5880,01 Kg/ha);
c) N5(97,38 kg N/ha; 4484,56 Kg/ha) e N6(85,51 Kg N/ha; 4430,44 Kg/ha);
d) $\mathrm{N} 8(48,79 \mathrm{~kg} \mathrm{~N} / \mathrm{ha} ; 2609,17 \mathrm{Kg} / \mathrm{ha})$ e N7(53,77 kg N/ha; $2464,00 \mathrm{Kg} / \mathrm{ha})$. 
TABELA 10 - Produtividade da cultura do milho no experimento $(\mathrm{Kg} / \mathrm{ha})$

\begin{tabular}{|c|c|c|c|c|c|c|}
\hline \multirow[t]{2}{*}{ Tratamentos } & \multicolumn{4}{|c|}{ Blocos } & \multirow[t]{2}{*}{ Média } & \multirow{2}{*}{$\begin{array}{l}\text { Teste* } \\
\text { Tukey }\end{array}$} \\
\hline & 1 & 2 & 3 & 4 & & \\
\hline N1 & 6116,67 & 6250,30 & 6287,93 & 6296,32 & 6237,81 & $\mathrm{~b}$ \\
\hline N2 & 8292,42 & 8050,34 & 7973,79 & 7847,66 & 8041,05 & a \\
\hline N3 & 5681,58 & 5875,42 & 6209,21 & 5753,84 & 5880,01 & b \\
\hline $\mathrm{N} 4$ & 6290,21 & 5927,21 & 6103,09 & 5964,11 & 6071,16 & b \\
\hline N5 & 4651,60 & 4569,76 & 4577,04 & 4139,85 & 4484,56 & c \\
\hline N6 & 4695,54 & 4236,08 & 4328,99 & 4461,13 & 4430,44 & c \\
\hline N7 & 2421,39 & 2399,89 & 2678,92 & 2355,79 & 2464,00 & $\mathrm{~d}$ \\
\hline N8 & 2687,28 & 2463,37 & 2753,14 & 2532,88 & 2609,17 & d \\
\hline
\end{tabular}

* Teste de Tukey a 5\%. Letras diferentes indicam diferença significativa entre

Observou-se, pelos resultados obtidos, que a produtividade alcançou um valor máximo no tratamento N2 (média de $8041,05 \mathrm{~kg} / \mathrm{ha}$ ), declinando no tratamento N1 (média de $6237,81 \mathrm{~kg} / \mathrm{ha}$ ). Isto indicou um excesso de nitrogênio aplicado no tratamento N1, causando diminuição na produtividade da cultura. Observando-se a tendência dos resultados na Figura 7 e recorrendo a estudos de modelos matemáticos aplicados na pesquisa biológica (PEREIRA \& ARRUDA, 1987), chegou-se à conclusão que a produtividade obtida poderia ser explicada por uma função quadrática ou exponencial quadrática.

Uma discussão mais aprofundada a respeito disto encontra-se no item 4.8 deste trabalho, que trata da obtenção da função de produção da cultura do milho para doses de nitrogênio. 


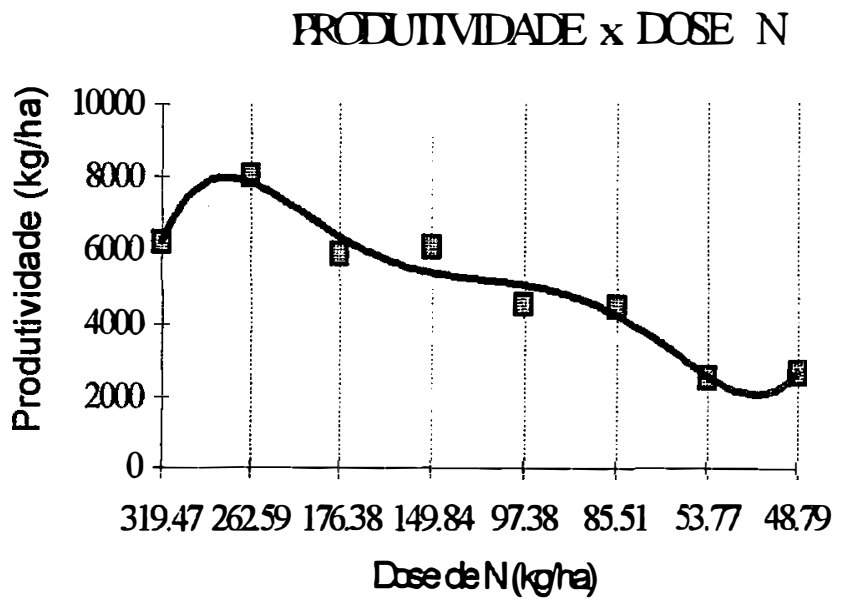

\section{娄 Produtividace Terdenaia}

Figura 7 - Produtividade da cultura do milho em função da dose de nitrogênio

\subsection{Comprimento das espigas e dos grãos}

O comprimento das espigas é apresentado na Tabela 11. A análise estatística dos resultados mostra que o tratamento N2 diferiu significativamente dos tratamentos N6, N7 e N8, não diferindo dos demais (Teste de Tukey ao nível de 5\% de significância). Apesar disso, deve-se considerar o comprimento de espigas como um dos principais motivos da produtividade diferenciada entre os diversos tratamentos. Esta afirmação baseia-se nos resultados do teste $F$, que apresentou diferenças significativas entre os tratamentos ao nível de significância de $1 \%$, bem como nos resultados da análise de produtividade. 
TABELA 11 - Comprimento de espigas dos tratamentos (mm)

\begin{tabular}{|c|c|c|c|c|c|c|}
\hline \multirow[t]{2}{*}{ Tratamentos } & \multicolumn{4}{|c|}{ Blocos } & \multirow[t]{2}{*}{ Média * } & \multirow{2}{*}{$\begin{array}{l}\text { Teste } \\
\text { Tukey }\end{array}$} \\
\hline & 1 & 2 & 3 & 4 & & \\
\hline N1 & 159,60 & 151,50 & 145,60 & 142,60 & 149,83 & $a b$ \\
\hline $\mathrm{N} 2$ & 189,30 & 160,50 & 153,50 & 122,10 & 156,35 & $\mathbf{a}$ \\
\hline N3 & 142,60 & 133,60 & 138,50 & 142,30 & 139,25 & $a b c$ \\
\hline N4 & 144,00 & 157,40 & 126,80 & 103,80 & 133,00 & $a b c$ \\
\hline N5 & 140,30 & 112,20 & 131,00 & 119,30 & 125,70 & $a b c$ \\
\hline N6 & 126,60 & 127,60 & 122,50 & 99,80 & 119,13 & b c \\
\hline N7 & 128,20 & 90,90 & 117,20 & 111,00 & 111,83 & c \\
\hline N8 & 98,70 & 103,90 & 121,60 & 102,80 & 106,75 & c \\
\hline
\end{tabular}

* Teste de Tukey a 5\%. Letras diferentes indicam diferença significativa entre médias

O comprimento de grãos não apresentou diferença significativa entre os tratamentos pelo teste de Tukey a 5\% de significância, conforme mostra a Tabela 12 .

TABELA 12 - Comprimento de grãos em cada tratamento (mm)

\begin{tabular}{|c|c|c|c|c|c|c|}
\hline Tratamentos & \multicolumn{4}{|c|}{ Blocos } & Média * & Teste \\
\hline & 1 & 2 & 3 & 4 & & \\
\hline N1 & 20,91 & 18,57 & 21,79 & 20,47 & 20,44 & a \\
\hline $\mathrm{N} 2$ & 20,65 & 20,57 & 20,24 & 20,54 & 20,50 & a \\
\hline N3 & 19,27 & 19,76 & 21,11 & 19,67 & 19,95 & a \\
\hline N4 & 18,27 & 20,40 & 20,35 & 19,73 & 19,69 & a \\
\hline N5 & 19,42 & 17,28 & 20,62 & 29,46 & 21,70 & a \\
\hline N6 & 18,77 & 17,69 & 18,42 & 16,85 & 17,93 & a \\
\hline N7 & 17,67 & 17,20 & 17,98 & 19,68 & 18,13 & a \\
\hline N8 & 16,39 & 18,74 & 18,85 & 16,17 & 17,54 & a \\
\hline
\end{tabular}

*Teste de Tukey a 5\%. Letras diferentes indicam diferença significativa entre médias

Não se evidenciou, neste caso, a influência da dose de nitrogênio sobre o 
comprimento dos grãos. As plantas, portanto reagiram de outra forma à adubação nitrogenada, produzindo grãos mais pesados e espigas mais longas à medida em que a dose de nitrogênio aplicada permitiu isto. Um aumento das doses de nitrogênio causou aumento do peso dos grãos e do comprimento de espigas.

\subsection{Peso de mil grãos}

A Tabela 13 mostra os resultados da pesagem de mil grãos em cada tratamento. Os tratamentos $\mathrm{N} 1$ e N2 diferiram dos tratamentos N6, N7 e N8, pelo teste de Tukey ao nível de $5 \%$ de significância, evidenciando a influência do nitrogênio no acúmulo de matéria seca, conforme afirmam STAPLETON et al.(1983). Os cinco primeiros tratamentos (N1 a N5) não diferiram significativamente entre si.

Houve maior dificuldade em identificar diferenças significativas entre os tratamentos que utilizaram as maiores doses de nitrogênio. $\mathbf{O}$ teste de Tukey foi feito considerando-se níveis de significância de 5\%, identificando diferenças significativas num universo de $95 \%$ das ocorrências.

TABELA 13 - Peso de mil grãos em cada tratamento (g)

\begin{tabular}{|c|c|c|c|c|c|c|}
\hline \multirow[t]{2}{*}{ Tratamentos } & \multicolumn{4}{|c|}{ Blocos } & \multirow[t]{2}{*}{ Média* } & \multirow{2}{*}{$\begin{array}{l}\text { Teste } \\
\text { Tukey }\end{array}$} \\
\hline & 1 & 2 & 3 & 4 & & \\
\hline N1 & 260,78 & 270,04 & 283,27 & 302,51 & 279,15 & $\mathbf{a}$ \\
\hline N2 & 296,87 & 294,77 & 261,19 & 254,01 & 276,71 & a \\
\hline N3 & 247,68 & 230,00 & 277,08 & 266,86 & 255,41 & $a b$ \\
\hline N4 & 272,46 & 252,41 & 266,98 & 202,46 & 248,58 & $a b$ \\
\hline N5 & 232,51 & 216,09 & 254,48 & 237,85 & 235,23 & $a b$ \\
\hline N6 & 252,43 & 220,59 & 237,77 & 214.09 & 236,93 & b \\
\hline N7 & 212,77 & 211,59 & 223,19 & 193,36 & 210,23 & b \\
\hline N8 & 215,25 & 214,10 & 238,44 & 231.49 & 222,60 & b \\
\hline
\end{tabular}

* Teste de Tukey a $5 \%$. Letras diferentes indicam diferença significativa entre médias 


\subsection{Teor de nitrogênio nos grãos}

A Tabela 14 mostra os resultados da análise do teor de nitrogênio nos grãos de cada tratamento. Os tratamentos N1 a N4 não diferiram entre si pelo teste de Tukey ao nível de 5\% de significância. O tratamento N4 foi superior aos tratamentos N5, N6, N7 e N8. Os tratamentos N1, N2 e N3 foram superiores aos tratamentos N6, N7 e N8. Houve portanto, uma influência da adubação nitrogenada nos teores de nitrogênio nos grãos.

TABELA 14 - Teor de nitrogênio (\%) nos grãos de cada tratamento

\begin{tabular}{|c|c|c|c|c|c|c|}
\hline \multirow[t]{2}{*}{ Tratamentos } & \multicolumn{4}{|c|}{ Blocos } & \multirow[t]{2}{*}{ Média * } & \multirow{2}{*}{$\begin{array}{l}\text { Teste } \\
\text { Tukey* }\end{array}$} \\
\hline & 1 & 2 & 3 & 4 & & \\
\hline N1 & 1,45 & 1,50 & 1,49 & 1,48 & 1,48 & $a b$ \\
\hline N2 & 1,46 & 1,48 & 1,49 & 1,45 & 1,47 & $a b$ \\
\hline N3 & 1,47 & 1,50 & 1,49 & 1,46 & 1,48 & $a b$ \\
\hline N4 & 1,51 & 1,50 & 1,53 & 1,49 & 1,51 & a \\
\hline N5 & 1,46 & 1,42 & 1,41 & 1,47 & 1,44 & b \\
\hline N6 & 1,29 & 1,28 & 1,27 & 1,24 & 1,27 & c \\
\hline N7 & 1,17 & 1,15 & 1,16 & 1,12 & 1,15 & $d$ \\
\hline N8 & 1,18 & 1,16 & 1,15 & 1,11 & 1,15 & d \\
\hline
\end{tabular}

* Teste de Tukey a $5 \%$. Letras diferentes indicam diferença significativa entre médias

Para as condições do experimento, os resultados obtidos permitem afirmar-se que foi possível obter grãos com maior teor de proteína à medida em que se aumentou a dose de nitrogênio aplicada, dentro de certos limites. Esse resultado apresenta certa relevância para as indústrias alimentícias. 
O incremento da dose de nitrogênio aumentou o peso dos grãos, auxiliando a explicação das diferenças de produtividade ocorridas entre os tratamentos no experimento. Este resultado e o comprimento das espigas merecem especial atenção.

Espigas mais compridas têm também maior número de grãos. Os dois fatores, atuando em conjunto, podem explicar as diferenças entre os tratamentos extremos(maiores e menores doses).

\subsection{Função de produção para o fator doses de nitrogênio}

Primeiramente foram ajustadas as funções para estimar a dose de nitrogênio em relação à distância da linha de fertirrigação. Foi ajustada uma função para cada linha de fertirrigação, devido à diferença de doses aplicadas em cada linha (L1 e L3). Utilizando recursos matemáticos citado por KREYSZIG(1993) e os resultados coletados no campo, chegou-se às seguintes funções:

$$
\begin{array}{ll}
\text { Para L1: } & \text { DN }=e^{(6,049-0,198 X)} \\
\text { Para L3 : } & \text { DN }=e^{(5,838-0,187 X)}
\end{array}
$$

onde:

$$
\begin{aligned}
& \mathrm{DN}=\text { dose de nitrogênio }(\mathrm{kg} / \mathrm{ha}) \\
& \mathrm{x}=\text { distância em relação à linha de fertirrigação. }
\end{aligned}
$$

Em seguida integrou-se as funções obtidas nos intervalos correspondentes a cada tratamento $(0-3 \mathrm{~m} ; 3-6 \mathrm{~m} ; 6-9 \mathrm{~m}$ e 9-12 $\mathrm{m}$ em relação à linha de fertirrigação). Logo após, dividiu-se o resultado da integração em cada intervalo pelo 
comprimento das parcelas (3 metros). Assim, chegou-se à dose média aplicada em cada parcela, que é apresentada na Tabela 15.

A partir dessa tabela e dos resultados de produtividade em cada tratamento foi possível estimar a função de produção para as doses de nitrogênio na cultura do milho. A função obtida foi:

$$
f(x)=e^{\left(7,341+0,0129 x \cdot 0,000026 x^{2}\right)}
$$

onde:

$$
\begin{aligned}
& f(x)=\text { produtividade }(\mathrm{kg} / \mathrm{ha}) \\
& \mathrm{x}=\text { dose de nitrogênio }(\mathrm{kg} / \mathrm{ha})
\end{aligned}
$$

TABELA 15 - Dose média de nitrogênio aplicada em cada

\begin{tabular}{lc}
\hline Tratamento & $\begin{array}{c}\text { Dose N média } \\
(\mathrm{kg} / \mathrm{ha})\end{array}$ \\
\hline N1 & 319,47 \\
N2 & 262,59 \\
N3 & 176,38 \\
N4 & 149,84 \\
N5 & 97,38 \\
N6 & 85,51 \\
N7 & 53,77 \\
N8 & 48,79 \\
\hline
\end{tabular}

Com o uso de técnicas de diferenciação matemática foi possível determinar a dose de nitrogênio que proporcionou a máxima produtividade para as condições do experimento. A Figura 7 (pág. 42) mostra o comportamento dos resultados obtidos. 
A derivada de primeira ordem da função de produção obtida, utilizada para estimar o ponto de máxima produtividade, é:

$$
f^{\prime}(x)=(-0,082 x+19,895) e^{\left(0,0129 x-0.000026 x^{2}\right)}
$$

onde:

$$
\begin{aligned}
f^{\prime}(x)= & \text { taxa de variação da produtividade em função da variação da dose } \\
& \text { de nitrogênio; } \\
x= & \text { dose de nitrogênio aplicada; }
\end{aligned}
$$

Igualando-se a derivada de primeira ordem a zero e efetuando-se os cálculos, obteve-se o ponto de máxima produtividade:

$$
\begin{gathered}
f^{\prime}(x)=0 \Rightarrow x=242,6 \mathrm{~kg} \mathrm{~N} / \mathrm{ha} \\
f(242,6)=7633.61 \mathrm{~kg} \text { grãos } / \mathrm{ha}
\end{gathered}
$$

A partir do ponto de máxima produtividade, qualquer acréscimo na dose de nitrogênio causará um decréscimo na produtividade. Deve-se observar que a precisão da estimativa está ligada à precisão do modelo matemático utilizado. $\mathrm{O}$ comportamento do modelo deve ser tal que permita máxima semelhança com a realidade. Para que isto seja possível, deve-se observar dois detalhes importantes: 1) o modelo deve ajustar-se bem aos resultados obtidos; 2) a extrapolação para além dos limites dos resultados observados sejam coerentes com a realidade.

O modelo utilizado no experimento apresentou coeficiente de correlação $\left(r^{2}\right)$ igual a 0,9375 . Observa-se que os resultados estimados tiveram uma boa correlação com os observados no experimento (Ver Tabela 16).

Modelos matemáticos são ferramentas importantes no estudo de fatores 
produtivos, servindo como instrumento de auxílio nas decisões. Percebe-se, porém, que a extrapolação de resultados obtidos é limitada a ambientes que apresentam as mesmas condições do espaço amostral utilizado na estimativa do modelo. $\mathrm{O}$ uso de um modelo matemático auxiliou a compreensão dos resultados de produtividade obtidos no experimento, permitindo o estabelecimento de relações quantitativas entre a dose do fertilizante utilizado e a produtividade da cultura do milho. A função de produção também pode ser associada a estudos econômicos, obtendo-se o ponto de máxima renda líquida da atividade produtiva em questão.

TABELA 16 - Dados observados e estimados de produção em função da dose de nitrogênio

\begin{tabular}{cccc}
\hline Dose de N & $\begin{array}{c}\text { Prod. Observada } \\
(\mathrm{kg} / \mathrm{ha})\end{array}$ & $\begin{array}{c}\text { Prod. Estimada } \\
(\mathrm{kg} / \mathrm{ha})\end{array}$ & $\begin{array}{c}\text { Diferença } \\
(\%)\end{array}$ \\
\hline 319,47 & 6237,80 & 6691,38 & 7,27 \\
262,59 & 8041,05 & 7597,84 & $-5,51$ \\
176,38 & 5880,19 & 6683,82 & 13,67 \\
149,84 & 6071,15 & 5944,27 & $-2,09$ \\
97,38 & 4484,56 & 4232,92 & $-5,61$ \\
85,51 & 4430,44 & 3842,84 & $-13,26$ \\
53,77 & 2463,99 & 2862,53 & 16,17 \\
48,79 & 2609,17 & 2720,30 & 4.26 \\
\hline
\end{tabular}

A utilização do sistema de aspersão em linha mostrou-se bastante interessante para a obtenção de funções de produção, dada a praticidade de manejo do sistema. Cuidados especiais devem ser tomados no sentido de se evitar locais e/ou horários em que o excesso de vento possa causar problemas de distribuição de água e, conseqüentemente, de fertilizante, bem como na escolha do tipo de aspersor a ser utilizado. 


\section{CONCLUSÕES}

Através da função de produção e do uso de técnicas de diferenciação matemática, chegou-se à conclusão de que à adubação nitrogenada teve influência positiva sobre a produção de grãos da cultura do milho, até uma determinada dose, acima da qual a produtividade diminuiu.

A função de produção estimou a máxima produtividade de grãos da cultura $(7663,65 \mathrm{~kg} / \mathrm{ha})$, para uma dose de $242,6 \mathrm{~kg} \mathrm{~N} / \mathrm{ha}$.

O nitrogênio apresentou influência sobre os seguintes parâmetros analisados: altura de plantas, altura de inserção das espigas nas plantas, comprimento de espigas, peso de grãos, teor de nitrogênio e proteína nos grãos, e produtividade.

O comprimento de grãos foi o único parâmetro que não apresentou diferenças significativas, no experimento. 


\section{REFERÊNCIAS BIBLIOGRÁFICAS}

ARAGÜÉS, R.; ROYO, A.; FACI, J. Evaluation of a triple line-source sprinkler system for salinity crop production studies. Soil Science Society of America Journal, Madison, 56 (2): 377-83, Mar./ Apr., 1992.

ARNON, I. Mineral nutrition of maize. Bern, International Potash Institute, 1975. $452 \mathrm{p}$.

BARROS, N.F. de; BRANDI, R.M.; COUTO, I.; FONSECA, S.M. Aplicação de fertilizantes minerais na formação de mudas de Eucaliptus grandis, Maiden ex Hook, através da água de irrigação. Revista Árvore, Viçosa, 1 (1) : 17-25, Mar., 1977.

BAR-YOSEF, B. Trickle irrigation and fertilization of tomatoes in sand dunes: water, N and $\mathrm{P}$ distributions in soil and uptake by plants. Agronomy Journal, Madison, 69: 486-91, May/June. 1977.

BAUDER, J.W.; HANKS, R.J.; JAMES, D.W. Crop production function determinations as influenced by irrigation and nitrogen fertilization using a continuous variable design. Soil Science Society of America Proceeding, Madison, 39: 1187-91, 1975.

BROADBENT, F.E.; NAKASHIMA, T.; ROLSTON, D.E., Effects of salinity and moisture gradients on nitrogen uptake by sorghum and wheat. Soil Science Society of America Journal, Madison, 146 : 232-40, 1988. 
CALHEIROS, C.B.M. Influência de lâminas de irrigação e de níveis de nitrogênio mineral sobre a produção de cana-de-açúcar (Saccharum oficinarum, L.). Piracicaba, 1990. 104 p. (Mestrado -Escola Superior de Agricultura "Luiz de Queiroz").

CAMARGO, A.P. de. Viabilidade e limitações climáticas para a cultura do milho. In: INSTITUTO BRASILEIRO DA POTASSA, ed.. Cultura e adubação do milho. Piracicaba, 1966, p.225-47.

CAMPOS. H. de. Aspectos da aplicação das superficies de resposta a ensaios fatoriais $3^{3}$ de adubação. Piracicaba, 1967. 82 p. (Livre-docência - Escola Superior de Agricultura 'Luiz de Queiroz"/USP).

COSTA, E.F. da \& BRITO, R.A.L. Aplicador portátil de produtos químicos via água de irrigação. Sete Lagoas, EMBRAPA, 1988. 19 p. (EMBRAPA. Circular técnica, 13).

COSTA, E.F. da; FRANÇA, G.E. de; ALVES, V.M. Aplicação de fertilizantes via água de irrigação. Informe Agropecuário, Belo Horizonte, 12 (39): 63-8, jun. 1986.

DAKER, A. A água na agricultura; manual de hidráulica agrícola, irrigação e drenagem. 3. ed. Rio de Janeiro, Ed. Freitas Bastos, 1970. 453 p.

DOOREMBOS, J. \& KASSAM, A.H. Yeld response to water. Rome, FAO, 1979. 193 p. (FAO. Irrigation and Drainage Paper, 33).

DOURADO NETO, D.; SAAD, A.M.; VAN LIER, Q. J. Fertirrigação: algumas considerações. In: _ ed. Curso de agricultura irrigada. Piracicaba, ESALQ/Depto. de Agricultura, 1991. p.185-90.

DOWNEY, L.A. Water use by maize at trhee plant densities. Experimental Agriculture, Cambridge, 7:161-9, 1971. 
ESTADOS UNIDOS. Department of Agriculture. Soil taxonomy; a basic system of soil classification to making and interpreting soil surveys. Washington, 1976. 754 p. (USDA. Agriculture Handbook, 436).

FANCELLI, A.L. Plantas alimentícias; guia para aula, estudos e discussão. Piracicaba, CALQ, 1986. $131 \mathrm{p}$.

FANCELLI, A.L. Milho e feijão: elementos de manejo em agricultura irrigada. In: DOURADO NETO, D.; SAAD, A.M.; VAN LIER, Q. J., ed.. Curso de agricultura irrigada. Piracicaba, ESALQ/ Depto. de Agricultura, 1991. p. 156-67.

FARIA, R.T. Estudo da lâmina de irrigação na cultura do trigo (Triticum aestivum, L.), utilizando o sistema de "aspersão em linha":. Piracicaba, 1981. 71 p. (Mestrado Escola Superior de Agricultura "Luiz de Queiroz"/USP).

FEITOSA $\mathrm{F}^{\circ}$, J.C.F. Uniformidade de distribuição de fertilizantes via água de irrigação por microaspersão, com injetores tipo venturi e tanque de derivação. Viçosa, 1990. 77 p. (M.S. - Universidade Federal de Viçosa).

FRATTINI, J.A. Cultura do milho; instruções sumárias. Campinas, CATI, 1975. 26 p.

FRENKEL, H.; MANTELL, A.; VINTEN, A. ; MEIRI, A. Double line source sprikler system for determining the separate and interactive effects of water and salinity on forage corn. Irrigation Science, Berlin, 11: 227-31, 1990.

FREY, D. Quimigatión. Fertilization y control de malezas y plagas con el água de riego. Agricultura de las Américas, Kansas, 12 : 14-8, 1981.

FRIZZONE, J.A. Fertirrigação. Piracicaba, ESALQ, 1984. 32p.

FRIZZONE, J.A. Funções de resposta do feijoeiro (Phaseolus vulgaris L.) ao uso de nitrogênio e lâminas de irrigação. Piracicaba, 1986. 133 p. (Doutorado - Escola Superior de Agricultura 'Luiz de Queiroz"/USP). 
FRIZZONE, J.A. Métodos de aplicação de fertilizantes via água de irrigação. In: SIMPÓSIO BRASILEIRO SOBRE FERTILIZANTES FLUIDOS, Piracicaba, 1993. Anais, coord. por G.C. Vitti e A.E. Boaretto. Piracicaba, POTAFOS, 1993. p. 211-31.

HAGIN, J. \& TUCKER, B. Fertilization of dryland and irrigated soils. Berlin, Springer-Verlag, 1982. $190 \mathrm{p}$.

HANKS, R.J.; KELLER, J.; RASMUSSEN, V.P.; WILSON, G.D. Line-source sprinkler for continuous variable irrigation-crop production studies. Soil Science Society of America Journal, Madison, 40: 426-9, 1976.

HANKS, R.J.; SISSON, D.V.; HURST, R.L. \& HUBBARD, K.G. Statistical analysis of results from irrigation experiments using the line-source sprinkler system. Soil Science Society of America Journal, Madison, 44: 886-8. July/Aug., 1980.

HENCKEL, P.A. Phisiology of plants under drought. Annual Review of Plant Phisiology, Palo Alto, 15: 363-86, 1964.

IGNATIEFF, V. \& PAGE, H. Efficient use of fertilizers. Rome, FAO, 1958. v. 1, 228 p. (FAO. Agricultural Studies, 43).

KEEPER, A. Os solos do Brasil e suas possibilidades para o milho. In: INSTITUTO BRASILEIRO DA POTASSA. Cultura e adubação do milho. Piracicaba, 1966. p. 249-61.

KREYSZIG, E. Advanced engineering mathematics. 7. ed. 1993. $1271 \mathrm{p}$.

KRUG, C.A. O milho no mundo. In: INSTITUTO BRASILEIRO DA POTASSA, ed. Cultura e adubação do milho. Piracicaba, 1966. p. 11-9.

LAUER, D.A. Line source sprinkler system for experimentation with sprinkler applied nitrogen fertilizers. Soil Science Society of America Journal, 47(1): 124-8, Jan./ Feb. 1983. 
LOUSADA, P.T. \& COUTO, C. Superficie de resposta. Piracicaba, ESALQ, 1983. $62 \mathrm{p}$.

MAGNUSSON, D.A. \& ASHER, J.B. Simulated water and solute distribution from a crossed triple line-source. Irrigation Science,Berlin, (11):31-6, 1990.

MAGNUSSON, D.A.; ASHER, J.B.; De MALACH, Y. A continuous two-variable design using the line-source concept. Agronomy Journal, Madison, 80:132-3, 1988.

MAIA, P.C.S.; FRIZZONE, J.A.; DOURADO NETO, D. Aplicação de fertilizantes e herbicidas via água de irrigação. In: FANCELLI, A.L., coord. Feijão irrigado. Piracicaba, FEALQ, 1990. p.

MALAVOLTA, E. \& GARGANTINI, H. Nutrição mineral e adubação. In: INSTITUTO BRASILEIRO DA POTASSA. Cultura e Adubação do Milho. Piracicaba, 1966. p. 381-428.

MENEZES, J.T. de. Efeito de diferentes lâminas de água na produção de sementes de cebola (Allium cepa L.). Piracicaba, 1990. 67 p. (Mestrado - Escola Superior de Agricultura “Luiz de Queiroz"/USP).

MORKOC, F.; BIGGAR, J.W.; MILLER, R.J. \& NIELSEN, D.R. 1985. Statistical analysis of sorghum yield: a stochastic approach. Soil Science Society of America Journal, 49:1342-8.

MOURA, M.V.T. de. Determinação do consumo de água na cultura da cenoura (Daucus carota L.) através dos métodos lisimétrico e balanço hídrico sob condições de campo. Piracicaba, 1992. 84 p. (Mestrado - Escola Superior de Agricultura “Luiz de Queiroz"/USP).

NELSON, L.W. The mineral nutrition of corn as related to its growth and culture. Advances in Agronomy, Ann Arbor, 8:321-75, Aug. 1956. 
PAIR, C.H.; HINZ, W.W.; REID, C.; FROST, K.R. Sprinkler irrigation. 3. ed. Washington, Sprinkler Irrigation Association, 1969. 444 p.

PEREIRA, A.R. \& ARRUDA, H.V. Ajuste de curvas na pesquisa biológica. Campinas, Fundação Cargill, 1987. 50 p.

RANZANI, G.; FREIRE, O.; KINJO, T. Carta de solos do município de Piracicaba. Piracicaba, ESALQ/ Depto. de Solos, Geologia e Fertilizantes, 1966. 85 p.

RESENDE, M.; FRANÇA, G.E.; ALVES, V.M.C. Considerações técnicas sobre a cultura do milho irrigado. Sete Lagoas, EMBRAPA/CNPMS, 1990. 24 p.

SEGARS, W.I. Fertigation supplements base fertilizer program. Better crops with plant food. Washington, 66(6): 6-9, 1982.

SHAW, E.J. Western fertilizer handbook. Sacramento, California Fertilizer Association, 1961. 163p.

SHAW, R.H. Climate requiriment. In: SPRAGUE, G.F. Corn and corn improvement. Madison, American Society of Agronomy, 1977. p. 591-617.

SILVA, A.F. da; VIANA, A.C.; CORREA, L.A.; CRUZ, J.C. Semeadura do milho. In: Recomendações técnicas para o cultivo do milho. $3^{\text {a }}$ ed. Sete Lagoas, EMPRES BRASILEIRA DE PESQUISA AGROPECUÁRIA/Centro Nacional de Pesquisa de Milho e Sorgo, 1987. p. 19-29.

STAPLETON, A.R.A.; WAGENET, R.J.; TURNER, D.L. Corn growth and nitrogen uptake under irrigated, fertilized conditions. Irrigation Science, Berlin, 4(1): 1-15. 1983.

VAN GENUCHTEN, M.T. A closed-form equation for predicting the hidraulic conductivity of unsaturated sois. Soil Science Society of America Journal, Madison, 41: 892-8, 1980. 
VASCONCELlOS, C.A.; SANTOS, H.L. dos; FRANÇA, G.E. de. Adubação e calagem. In: EMPRESA BRASILEIRA DE PESQUISA AGROPECUÁRIA/ Centro Nacional de Pesquisa de Milho e Sorgo, ed.. Recomendações técnicas para o cultivo do milho. $3^{\mathrm{a}}$ ed. Sete Lagoas, 1987. p. 43-51.

VIÉGAS, G.P. Técnica cultural. In: INSTITUTO BRASILEIRO DA POTASSA. Cultura e Adubação do Milho. Piracicaba, 1966. p. 263-332.

VIETS Jr., F.G.; BOAWN, L.C.; CRAWFORD, C.L. \& NELSON, C.E. Zinc deficiency in corn in central Washington. Agronomy Journal, Madison, 45: 559-65, Mai., 1953.

VIETS JR., F.G.; HUMBERT, R.P.; NELSON, C.E. Fertilizers in relation to irrigation practice. In: HAGAN, R.M.; HAISE, H.R.; EDMINSTER, T.W. Irrigation of agricultural lands. Madison, American Society of Agronomy, 1967. 1(11): 100923. 